\title{
Niveles de conservación y degradación de hábitat en los ecosistemas de una cuenca de alta biodiversidad en Tamaulipas (México)
}

Levels of conservation and habitat degradation in the ecosystems of a high biodiversity basin in northeastern Mexico

\author{
Glenda Nelly Requena Lara \\ grequena@uat.edu.mx \\ Juan Francisco Morales Pacheco \\ juanmorales101@hotmail.com \\ Instituto de Ecología Aplicada \\ Universidad Autónoma de Tamaulipas (México)
}

\section{Rafael Cámara Artigas}

rcamara@us.es

Departamento de Geografía Física y Análisis Geográfico Regional

Universidad de Sevilla (España)

\section{Carlos Zamora Tovar}

czamora@uat.edu.mx

Instituto de Ecología Aplicada

Universidad Autónoma de Tamaulipas (México) 


\title{
Resumen
}

Los ecosistemas con flujos de servicios ambientales óptimos ofrecen una adecuada calidad en sus hábitats que coadyuvan a mantener su biodiversidad. Esta calidad puede reducirse por los factores de mayor intensidad y cercanía al hábitat, lo que puede estudiarse con herramientas geoespaciales. Este trabajo evaluó los niveles de degradación relativa de hábitat en la cuenca Guayalejo-Tamesí (Tamaulipas, México), respecto a los factores adyacentes que amenazan su calidad, usando el modelador Habitat Quality del Toolbox InVest 1.005beta para ArcGis-9.2. Los ecosistemas con menor amenaza a su hábitat (degradación nula o menor a 20 \%) y con mejores oportunidades de conservación, representan el 77,3\% de la superficie de la cuenca. Particularmente, los hábitats montañosos (bosques templados y mesófilo) son los mejor conservados, pues más del 80 \% de su superficie se encuentra libre de degradación; destaca el bosque mesófilo de montaña, con un $94 \%$ de su superficie no degradada, debido a su escasa exposición a factores amenazantes. Se concluye que, a pesar del uso intensivo del territorio de la cuenca, existen ecosistemas bien conservados, especialmente en zonas aisladas; la mayoría de ellas carecen de protección legal, por lo que se encuentran expuestas a la ampliación y agravamiento de las amenazas antropogénicas estudiadas.

Palabras clave: servicios ambientales; degradación del hábitat; cuenca Guayalejo-Tamesí; InVest 1.005 beta.

\begin{abstract}
Ecosystems with optimal environmental service flows offer adequate quality in their habitats to maintain their biodiversity. Anthropogenic factors of higher intensity and proximity to the habitat can reduce this quality, and we can study this degradation with geospatial tools. This work evaluated the levels of relative degradation of habitat in the Guayalejo-Tamesí basin (Tamaulipas, Mexico), concerning the adjacent factors that threaten its quality. We used the geospatial tool Habitat Quality of the Toolbox InVest 1.005beta for ArcGis-9.2. The ecosystems with less threat to their habitat (zero degradation or less than 20\%) and with better conservation opportunities, represent $77,3 \%$ of the surface of the basin. Mountainous habitats (temperate and cloud forests) are the best-preserved since more than $80 \%$ of their surface is free of degradation. The mountain cloud forest, with $94 \%$ of its surface not degraded, due to its low exposure to threatening factors. In conclusion, in spite of the intensive use of the territory of the basin, there are well-conserved ecosystems, especially in isolated areas. The lack of legal protection at the majority of these sites exposes it to enlargement and aggravation of the anthropogenic threats.
\end{abstract}


Key words: ecosystem services; habitat degradation; Guayalejo-Tamesí basin; InVest 1.005 beta.

\section{Introducción}

La persistencia de las especies y sus poblaciones depende de la capacidad de los ecosistemas para proporcionarles un hábitat adecuado para su desarrollo. La cuantificación de dicha capacidad se conoce como "calidad del hábitat" (Hall et al., 1997), y puede ser interpretada en el mismo sentido que la "integridad del hábitat", ésta entendida como un ecosistema poco alterado, con estructura y funciones que no han variado prácticamente a lo largo de su historia. Por ello, un ecosistema de buena calidad cuenta con mejor capacidad para prestar niveles óptimos de Servicios Ambientales (SSAA, también llamados "servicios ecosistémicos"), aunque eso no descarta que zonas con cierta degradación -como un cultivo perenne o un pastizal- puedan tener un buen nivel de SSAA, por ejemplo, como hábitat para la biodiversidad (Tallis et al., 2010).

De acuerdo con Nelleman (2001, McKinney (2002), Forman et al. (2003) y Tallis et al. (2010), se atribuye que la calidad de un hábitat en general disminuye conforme se aproxima a factores casi siempre antropogénicos, considerados como amenazas de diversos grados según su intensidad. Por lo tanto, los ecosistemas con mayor calidad de hábitat se mantienen relativamente intactos, mientras que su variabilidad de estructura y funciones ocurre en rangos de tiempo amplios (Tallis et al., 2010). Ejemplo de un ecosistema con alta calidad es un bosque nativo en la zona núcleo de un espacio natural protegido, mientras que el caso contrario es un matorral que rodea una mina a cielo abierto.

En el estado mexicano de Tamaulipas coinciden factores geográficos y ecológicos que le dotan de una alta riqueza de especies y de ecosistemas; es un sitio donde convergen ambientes templados con tropicales, de manera que cuenta con tipos de vegetación de las seis zonas ecológicas en que Toledo (1998) clasifica el territorio mexicano. Esta riqueza se concentra de forma importante en el sur del estado, enmarcada por la cuenca del río Guayalejo, cuyo caudal dio origen al segundo distrito de riego instalado en México y que, en sus montañas centrales alberga la Reserva de la Biósfera "El Cielo".

La Cuenca Guayalejo-Tamesí se sitúa sobre el Trópico de Cáncer, en el límite de las regiones biogeográficas Holártica y Neotropical. Esto, aunado a su cercanía al Golfo de México y al acentuado gradiente de altitud de la Sierra Madre Oriental - que alcanza hasta 3500 msnm-, le permiten una alta diversidad de ecosistemas, con comunidades vegetales que incluyen manglares, selvas, bosques templados y ecosistemas desérticos. La vecindad de ecosistemas es tan estrecha, 
que sus ecotonos se difuminan entre sí, produciendo paisajes diversos y de fehaciente belleza que, cuando son de difícil acceso por sus terrenos escarpados y rocosos, no son propios para el desarrollo de actividades económicas primarias. Por ello, se encuentran relativamente intactos y con una evidente calidad en sus hábitats (Requena, 2013).

Además de esta gran diversidad, los usos de suelo en los terrenos más planos de la cuenca han sido extensos e intensivos. De acuerdo con UNAM (2000), la cuenca prácticamente se divide por igual en vegetación con cierto grado de madurez y terrenos con uso humano, siendo estos últimos los que ocupan casi la mitad de su territorio, y que se ubican en llanuras, valles y bajadas con pendiente suave. Los usos de suelo más extendidos son la agricultura de riego -principalmente caña de azúcar y hortalizas- y de secano, así como la ganadería extensiva en pastizales cultivados e inducidos.

Aunque esta riqueza biológica es evidente, el hablar de la importancia de un ecosistema por sus valores intrínsecos podría ser insuficiente para convencer al público general de interesarse y esforzarse en su cuidado; por ello, Kiss (2004) plantea la importancia de que los estudios científicos deben considerar el cómo incentivar a las autoridades (tomadores de decisiones) a invertir en la conservación de la biodiversidad. De acuerdo con Martín-López et al. (2009), los altos valores ecológicos de los hábitats bien conservados pueden influir en sus valores socioeconómicos, al tiempo que su integridad o calidad pueden determinar preferencias sociales, que en conjunto atraigan la atención de las autoridades. Por ello, Arcidiacono et al. (2016), consideran que la construcción de modelos que evalúan la calidad y las amenazas al hábitat pueden informar y apoyar en las decisiones de las comunidades para buscar un desarrollo territorial sustentable.

Bajo la idea de que la conservación de los ecosistemas y sus SSAA son imprescindibles por ser el soporte de las actividades humanas, surgida a fines del siglo pasado (Basking, 1997; Daily, 1997), las Naciones Unidas organizó en 2005 la llamada Evaluación de los Ecosistemas del Milenio (EEM). Dentro de ese marco, algunos grupos de científicos de la EEM desarrollaron herramientas para analizar los SSAA de los ecosistemas, y proveer argumentos para la toma de decisiones sobre su conservación y uso perdurable (Kareiva et al., 2011). Al tratarse del análisis de elementos y fenómenos territoriales, algunas de esas herramientas se basan en los Sistemas de Información Geográfica (SIG) para evaluar diversos SSAA, así como su intensidad, calidad y valor socioeconómico. Una de ellas es el paquete llamado InVEST (Integrated Valuation of Ecosystem Services and Trade-offs) para el software ArcGis de ESRI, desarrollado por Kareiva et al. (2011). 
El algoritmo de InVEST Ilamado Biodiversity: habitat quality \& rarity, evalúa las amenazas a los ecosistemas bajo la premisa de que la calidad del hábitat se encuentra en función de su cercanía a los usos antropogénicos del terreno (aunque pueden incluirse disturbios naturales como incendios, plagas, etc.), así como a la intensidad de estos (Nelleman et al., 2001; Forman et al., 2003; Nelson et al., 2011). Esos factores inducen la formación de efectos de "frontera", que facilitan la entrada de elementos de degradación al hábitat, aunado a una tendencia a degradarse y aislarse del conjunto original; a su vez, se provoca la reducción en la capacidad de contribución del hábitat para proveer SSAA y permitir la supervivencia de las especies.

Este modelador asume además que, al proteger legalmente un hábitat con baja degradación, se está protegiendo su calidad, y por lo tanto, sus componentes elementales (Nelson et al. 2011), entre los que se incluyen sus poblaciones y su poza genética. Su protección redundará en el aseguramiento de la provisión de SSAA que, directa o indirectamente, inciden en las actividades socioeconómicas de una región. Por esta razón, el conocer la distribución territorial de la calidad de un hábitat y sus sitios de degradación, es imprescindible para los tomadores de decisiones en el ordenamiento del territorio. Como una respuesta a esta necesidad, el objetivo del presente trabajo fue analizar el efecto de las actividades humanas sobre los hábitats de la cuenca GuayalejoTamesí, representados por los tipos de cobertura del suelo, y evaluados para establecer su nivel de degradación relativa, utilizando herramientas de SIG especializadas.

\section{Metodología}

\section{1 Área de estudio}

La porción tamaulipeca de la cuenca Guayalejo-Tamesí abarca alrededor de quince mil kilómetros cuadrados en el sur del estado mexicano de Tamaulipas (Figura 1.), entre los paralelos $21^{\circ} 11^{\prime}$ y $23^{\circ} 54^{\prime}$ de Latitud Norte y los meridianos $97^{\circ} 47^{\prime}$ y $99^{\circ} 52^{\prime}$ de Longitud Oeste. Algunas porciones de esta (aproximadamente 5.52\%, de acuerdo con Adame y Estrada, 2003) pertenecen a los estados de Nuevo León (al oeste), Veracruz (al sureste) y San Luis Potosí (al suroeste). 
Figura 1. Localización geográfica del área de estudio

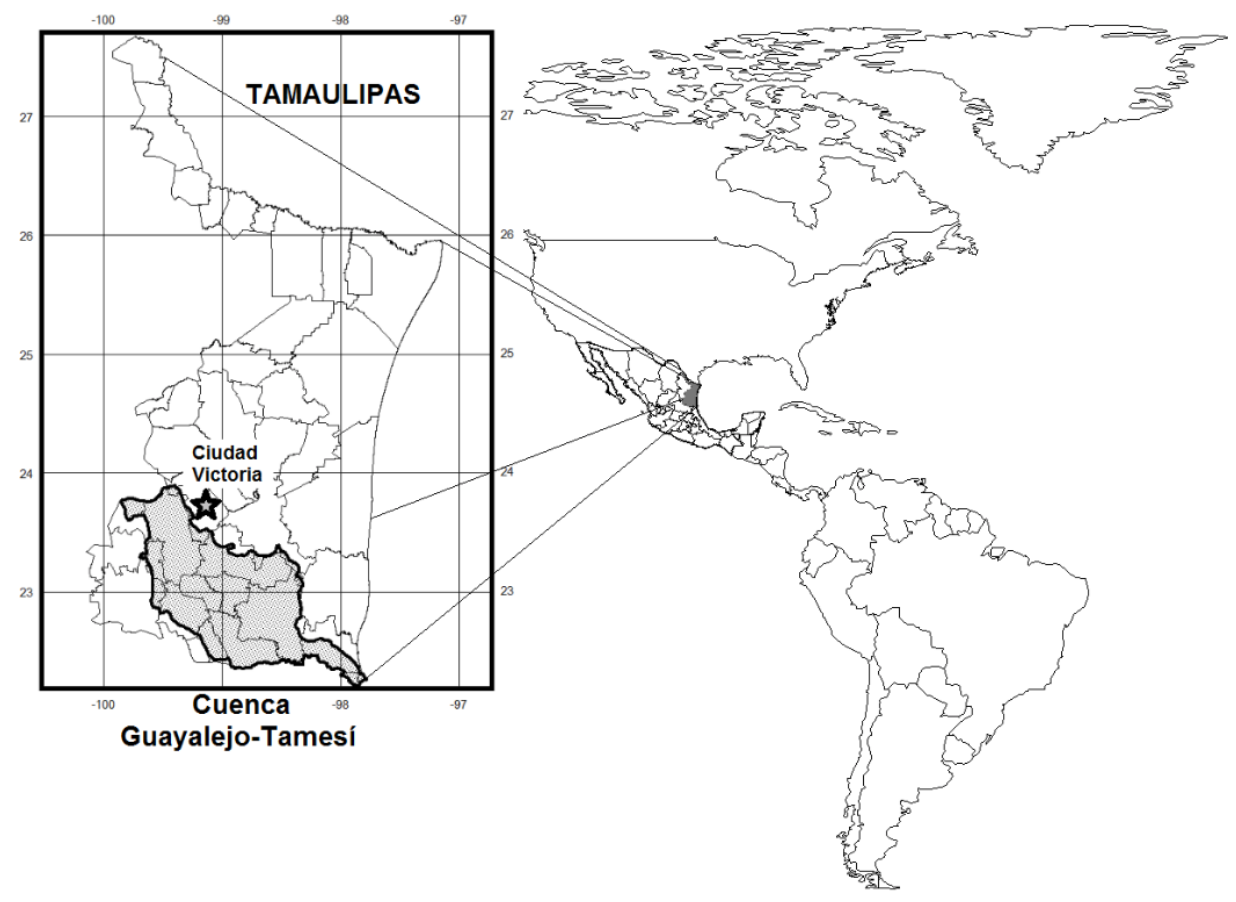

Fuente: elaboración propia con datos libres de ESRI e INEGI (2013)

La cuenca pertenece a dos provincias fisiográficas, tres subprovincias y una discontinuidad fisiográfica: de la Provincia de la Sierra Madre, la Subprovincia de la Gran Sierra Plegada Oriental; de la Llanura Costera del Golfo Norte, la Subprovincia de Llanuras y Lomeríos; así como una porción de la discontinuidad de la Sierra de Tamaulipas. Por lo tanto, el 35 \% del territorio del área de estudio es de tipo serranía, $30 \%$ de llanuras y $16 \%$ de bajadas, en elevaciones que van desde el nivel del mar, hasta alcanzar 3450 metros en la Gran Sierra Plegada (Figura 2).

En el territorio de la cuenca, predominan las rocas de origen sedimentario, donde dominan lutitas y calizas en diversas formaciones. En los basamentos de la Sierra Madre Oriental afloran las rocas más antiguas del estado, que son esquistos y gneises originados en el Precámbrico y el Paleozoico (Ramírez \& Jenchen, 2017); además, existen diversos tipos de rocas sedimentarias del Paleozoico y Cenozoico, con algunos afloramientos de basalto y brechas. Por su parte, en la llanura costera alberga rocas sedimentarias, con escasas manifestaciones volcánicas del Terciario y Cuaternario (SGM, 2011). 
Figura 2. Altitud sobre el nivel del mar en el área de estudio

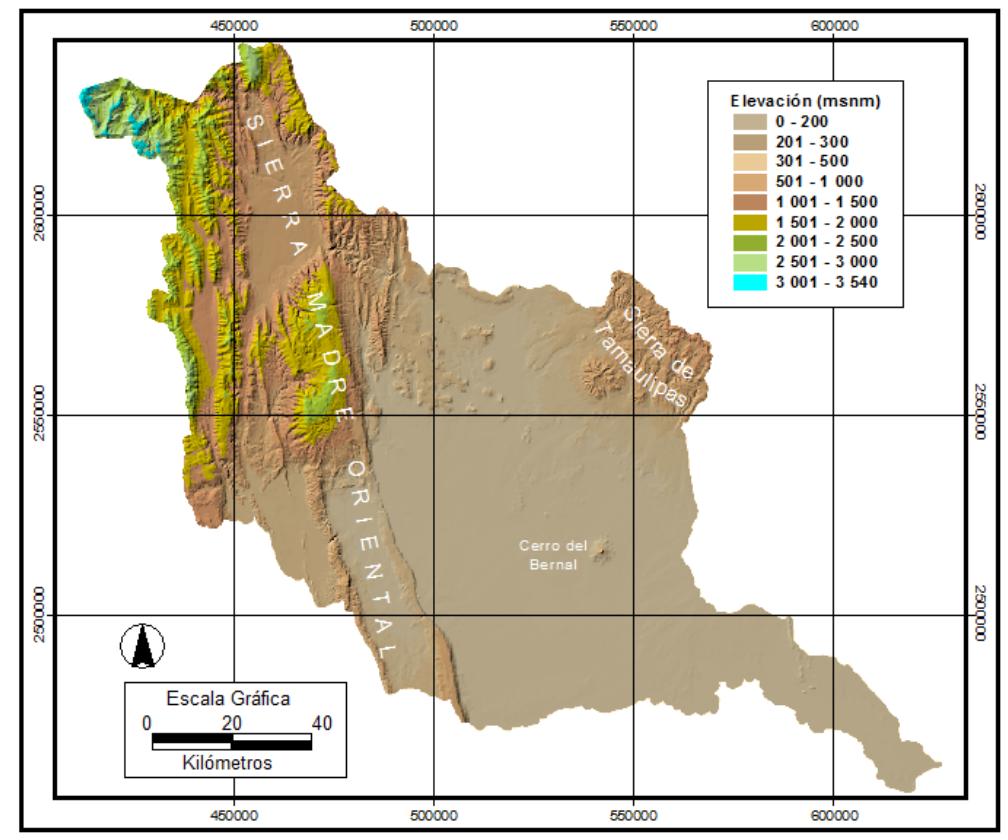

Fuente: elaboración propia con el modelo digital de elevación de Moreno (2003)

La mayor parte del área de estudio presenta suelos vertisoles y litosoles. Los primeros dominan las áreas montañosas, donde manifiestan vegetación boscosa bien conservada, mientras que los segundos se ubican en las áreas más planas, que permiten cultivos en riego y en secano, por su capacidad fértil. Aunque estos dos tipos predominan casi en el $70 \%$ del territorio, otras 20 unidades se presentan principalmente en las zonas con pendientes más bajas, como regosoles, rendzinas, cambisoles, etc. (INEGI, 2000).

Hidrológicamente, el río Guayalejo -el eje principal del área de estudio- es el mayor aportador hacia la región hidrológica del Río Pánuco, que nace en la altiplanicie mexicana (Arcos-Espinosa et al., 2017), y que fuera del territorio de la cuenca, presenta uno con los mayores niveles de alteración eco-hidrológica del país (Carbajal et al., 2015). Cuenta con un escurrimiento medio anual de 2999 millones de $\mathrm{m}^{3}$ y caudales de $72,9 \mathrm{~m}^{3}$ /seg en una de las estaciones del centro de la cuenca (UAT, 2001).

En cuanto a su clima, dominan las condiciones cálidas y húmedas, especialmente en las cuencas medias y bajas, aledañas al Golfo de México. La humedad del Golfo es retenida por las primeras estribaciones de la cordillera Sierra Madre (hasta $2500 \mathrm{msnm}$ ), donde la temperatura disminuye y la humedad se condensa, por lo que en los valles altos de la ladera opuesta dominan los climas secos y áridos. Por otra parte, en las montañas de mayor altitud (hasta $3450 \mathrm{msnm}$ ) del extremo oeste existen climas semifríos y con escasa humedad (INEGI, 1983). 
Estas características permiten que se desarrolle en la cuenca una importante variedad de ecosistemas, por lo que en lo que respecta a la vegetación, en este territorio se encuentran los reinos Holoártico (región Mesoamericana de Montaña) y Neotropical (regiones Xerofítica Mexicana y Caribea), de acuerdo con Rzedowski (2006). En concordancia con esto, en el área de estudio concurren siete de las diez zonas ecológicas reconocidas por las autoridades ambientales mexicanas (GIOT, 2000): templado subhúmeda, cálido-subhúmeda, semiárida, templado-húmeda, árida, humedales, cálido-húmeda y halo-gipsófila (Requena, 2007).

El encuentro de esta variedad florística es evidente al inventariar los tipos de vegetación y uso del suelo de la cuenca, pues se registran 20 de los 24 principales tipos en el Inventario Nacional Forestal (UNAM, 2000). Sin embargo, cabe mencionar que éste y otros inventarios de comunidades vegetales se elaboran a escalas medias (1:250 000), por lo que no son evidentes algunos ecosistemas relictuales o altamente fragmentados (Requena, 2013), como son algunos bosques de Abies spp., chaparrales de Quercus spp. o vegetación de galería. Por esta razón, Requena (2013) elaboró un mapa de vegetación y uso de suelo, a través de la clasificación experta de imágenes de satélite en una serie multitemporal (2006-2011) del sensor MODIS y 19 factores ecogeográficos para la cuenca, para una resolución final de pixel de 100m, clasificando la superficie del territorio estudiado como se observa en la siguiente tabla.

En cuanto al medio social, de acuerdo con los datos del censo oficial más reciente (INEGI, 2010), la población es de 810159 habitantes, concentrada principalmente en la zona sur, por la conurbación de tres municipios altamente industrializados (Ciudad Madero y los puertos de Tampico y Altamira), así como en las cabeceras municipales. Esta población urbana representa el 83,64 \% de la cuenca, por lo que las actividades económicas se ubican mayoritariamente en la cuenca media y baja, dedicadas al ámbito agropecuario en gran parte de ese territorio. Sin embargo, las actividades económicas secundarias y terciarias son las causantes de esa distribución poblacional, y se fomentaron con el crecimiento de los núcleos urbanos: principalmente el comercio y agroindustria en el centro, así como comercio, industria química y petroquímica en el extremo sureste (Requena, 2013).

El uso del agua en la cuenca se destina, como en otros lugares del mundo, a la actividad agropecuaria casi en un $80 \%$, seguido del sector industrial y uso público urbano (8\% en cada caso), mientras que el resto se destina a la acuacultura, generación de electricidad y actividades recreativas (Vera, 2004). Si se suma el uso agrícola del agua superficial con la subterránea (69 \%), aunado con el clima semicálido, se entiende que en la cuenca sean posibles los ciclos de riego 
durante todo el año; esto permite la existencia de tres distritos de riego que integran casi $750 \mathrm{~km}$ de canales, tres embalses de almacenamiento y seis derivadores, ubicados en la cuenca media, donde se desarrolla la mayor parte de la mencionada actividad.

\section{Tabla 1. Clasificación del área de estudio por sus tipos de vegetación y uso de suelo}

\section{(Requena, 2013). Las abreviaciones se utilizarán a continuación en este documento}

\begin{tabular}{|c|c|c|c|}
\hline Vegetación y uso de suelo (LULC) y algunas especies representativas & Abreviación & Hectáreas & $\%$ \\
\hline Agricultura de riego (incluye riego eventual) & AGR & 169338 & 11,36 \\
\hline Agricultura de temporal (secano) con cultivos anuales & AGTA & 269254 & 18,06 \\
\hline $\begin{array}{l}\text { Agricultura de temporal (secano) con cultivos permanentes y } \\
\text { semipermanentes }\end{array}$ & AGTP & 8793 & 0,59 \\
\hline Asentamiento humano (mancha urbana) & URB & 20606 & 1,38 \\
\hline Bosque con vegetación secundaria de pino, encino y/o chaparral & BPEvs & 32652 & 2,19 \\
\hline Bosque de encino (Quercus spp.) & $\mathrm{BE}$ & 83004 & 5,57 \\
\hline Bosque de pino (Pinus spp.) & $\mathrm{BP}$ & 30184 & 2,02 \\
\hline Bosque de pino-encino (incluye encino-pino) & BPE & 71904 & 4,82 \\
\hline Bosque de táscate (Juniperus spp.) & BT & 3576 & 0,24 \\
\hline Bosque húmedo de montaña & BMM & 28857 & 1,94 \\
\hline Cuerpo de agua & AGUA & 30785 & 2,06 \\
\hline $\begin{array}{l}\text { Manglares (Rhizophora mangle, Laguncularia racemosa, Conocarpus } \\
\text { erectus, Avicennia germinans) }\end{array}$ & MAN & 257 & 0,02 \\
\hline Matorral desértico rosetófilo (incluye con y como vegetación secundaria) & MDR & 55072 & 3,69 \\
\hline Matorral submontano & MSM & 79377 & 5,32 \\
\hline Mezquital (incluye huizachal), (Prosopis spp., Vachelia farnesiana) & MZQ1 & 7708 & 0,52 \\
\hline Mezquital (incluye huizachal) con y como vegetación secundaria & MZQvs & 42860 & 2,87 \\
\hline Palmar natural (Sabal spp) y como vegetación secundaria & PALM & 7698 & 0,52 \\
\hline Pastizal cultivado & PZC & 64517 & 4,33 \\
\hline Pastizal inducido & $\mathrm{PZI}$ & 10870 & 0,73 \\
\hline $\begin{array}{l}\text { Popal-tular: Tular (Typha spp.) y otra vegetación semisumergida y } \\
\text { sumergida }\end{array}$ & TUL & 14687 & 0,99 \\
\hline Selva alta y mediana subperennifolia & SAMS & 32128 & 2,15 \\
\hline Selva baja caducifolia y subcaducifolia & SBC & 115885 & 7,77 \\
\hline $\begin{array}{l}\text { Selva baja caducifolia y subcaducifolia con vegetación secundaria arbustiva } \\
\text { y herbácea }\end{array}$ & SBCvs & 99690 & 6,69 \\
\hline $\begin{array}{l}\text { Selva baja espinosa, incluye huizachal con y como vegetación secundaria } \\
\text { arbustiva y herbácea }\end{array}$ & SBEhzch & 60547 & 4,06 \\
\hline $\begin{array}{l}\text { Selva mediana caducifolia y subcaducifolia, incluye vegetación secundaria } \\
\text { arbustiva y herbácea }\end{array}$ & SMSC & 79550 & 5,34 \\
\hline Suelo aparentemente desnudo (permanente y octubre 2011) & DESN & 38358 & 2,57 \\
\hline Superficies quemadas (octubre 2011) & QUE & 31932 & 2,14 \\
\hline $\begin{array}{l}\text { Vegetación de galería o riparia (incluye bosque, selva y vegetación de } \\
\text { galería) }\end{array}$ & RIPA & 324 & 0,02 \\
\hline Zona inundable & $\mathrm{INU}$ & 596 & 0,04 \\
\hline
\end{tabular}

Fuente: Requena (2013)

Los sistemas de riego junto con los de secano propician el cultivo de 59 especies y variedades de granos, hortalizas, frutales, rosetófilos (Agave tequilana y Aloe sp.) y caña de azúcar. Dentro de estos destacan, por su alto valor comercial hortalizas y tubérculos, distintas variedades de tomate, 
chile, cebolla y aguacate; por su superficie sembrada resaltan la caña de azúcar, el cártamo, la soya y el sorgo en grano SAGARPA, 2004).

Por su parte, en la actividad pecuaria se produce principalmente vacuno de doble propósito (carne y leche), porcino, ovino, avícola (carne y huevo) y caprino; otros productos de origen animal son la miel de abeja y en medida incipiente pescado y crustáceos cultivados en agua dulce (SAGARPA, 2004). La actividad forestal extrae maderas de pino (Pinus spp.), encino (Quercus spp), mezquite (Prosopis spp.), cedro blanco (Cedrela odorata), Sabal spp., entre otras; sin embargo, el cultivo forestal es incipiente, con especies exóticas en pequeñas superficies de la cuenca media (INFDMP, 2005); por su parte, especies no maderables son extraídas artesanalmente, como el orégano (Lippia sp.), lechuguilla (Agave lechuguilla) y piñón (Pinus sp.) en el altiplano; así como palmilla cameador (Chamaedorea sp.) o chile piquín (Capsicum annuum var. glabriusculumgra) en las selvas y matorrales de la cuenca (OEIDRUS, 2011).

La actividad minera no petrolera en la cuenca es de poca importancia relativa a otros estados del país, tanto en volumen como en ley; se extraen cal, grava, barita, fluorita y yeso, así como plata, oro, plomo, mercurio, cobre y zinc en menores cantidades. En el caso de la extracción no metálica se trata en general de minas a cielo abierto (INFDMP, 2005; UAT, 2001).

En cuanto a las actividades industriales, estas se llevan a cabo dentro de las áreas urbanas principales, destacando la agroindustria del azúcar y etanol de caña, las procesadoras de cítricos, las de zumo de aloe (altiplano y cuenca media), así como la tequilera de exportación exclusiva, en la cuenca media (OEIDRUS, 2011). Por su parte, las industrias maquiladoras de textiles, maquinaria y equipo destacan en las cuencas media y baja. Sin embargo, el grupo industrial de mayor importancia económica a nivel nacional desde los años 80 es el dedicado a la generación de químicos y petroquímicos, ubicado en la zona conurbada del sur. Este grupo de industrias están asociadas a la Refinería Madero de PEMEX, que fue la primera en dedicarse a la petroquímica en la región desde los años 60, produciendo coque; además, se complementa con una red troncal de ductos abastecedores para el norte y noreste de México (Martínez, 2001).

\subsection{Método}

Para evaluar el nivel de degradación del hábitat, se utilizó el modelador Biodiversity: habitat quality \& rarity, que es parte de la herramienta INvEST 1.005 para ArcGis 9.2 de ESRI y que se basa en la identificación de los factores que amenazan a los ecosistemas y su nivel de afectación sobre los hábitats de la cuenca. Tales amenazas se evalúan bajo la idea de que la calidad del hábitat está en función de su cercanía a los usos antropogénicos del terreno y de la intensidad de estos 
(Nellleman et al., 2001 y Nelson et al., 2011); dichos factores inducen la formación de efectos de "frontera" que facilitan la entrada de elementos de degradación del hábitat, aunado a una tendencia a degradarse y aislarse del conjunto; esto a su vez provoca la reducción en la capacidad de contribución del hábitat en la sobrevivencia de las especies.

Se utilizaron las especificaciones para el nivel básico (que en el algoritmo se le llama Tier 1), diseñado para sitios con datos relativamente escasos. De acuerdo con los diseñadores de la herramienta (Tallis et al., 2010), el Tier 1 del algoritmo identifica los hábitats con diferentes niveles de producción de SSAA en el área estudiada, así como de factores ("amenazas") que pueden comprometer ese flujo de servicios. Además, para simplificar la modelación, en este Tier se asume que el nivel de degradación es el mismo para toda la biodiversidad contenida en una unidad de superficie de un hábitat dado.

El análisis se realiza sobre los hábitats, representados en el presente estudio (como sugiere Tallis et al., 2010), por medio del mapa de Vegetación y Uso de Suelo (LULC, por sus siglas en inglés) elaborado por Requena (2013) para la cuenca. Esta autora generó el modelo digital del LULC en formato raster, a partir de una clasificación supervisada experta de imágenes de satélite de mediana resolución. Además de la representación de los hábitats, algunas de las coberturas antropogénicas de este modelo se usaron como mapas de amenazas a la biodiversidad: distintos tipos de agricultura, pastizales cultivados (representando zonas ganaderas), áreas urbanas y zonas quemadas (aunque su origen no necesariamente sea antropogénico), como se señala posteriormente.

El modelador Biodiversity: habitat quality \& rarity, otorga a cada pixel del mapa LULC un valor relativo (O a 1) de calidad (HQ). El nivel de calidad es dado acuerdo con su localización respecto a las amenazas que le rodean, en conjunto con su impacto sobre el tipo de hábitat que representa la celda (Nelson et al., 2011). Además, contabiliza el nivel total de amenazas "Dxj" en cada celda " $x$ " con determinado LULC o hábitat "j", de acuerdo con la siguiente ecuación:

$$
D_{x j}=\sum_{r=1}^{R} \sum_{y=1}^{Y_{r}}\left(w_{r} / \sum_{r=1}^{R} w_{r}\right) r_{y} i_{r x y} \beta_{x} S_{j r}
$$

Donde:

$r_{1}, r_{2}, r_{3} \square R$ son los usos amenazantes a la calidad del hábitat $H Q$

$i_{\text {rxy }} \quad$ indica el impacto de la amenaza " $r$ " que se origina en la celda " $y$ ", "ry", la cual contiene un hábitat " $x$ ". 
y indexa todas las celdas en el mapa de la amenaza " $r$ ", e "Yr" indica el grupo de celdas en el mapa de la amenaza " $r$ ".

Wr es la ponderación del impacto relativo de " $r$ "

$\beta_{x} \quad$ es el nivel de accesibilidad a la celda " $x$ ", que puede mitigar el nivel de amenaza " $r$ " a esa celda. Para el presente trabajo se asumió que en la práctica no existen condiciones legales, institucionales, sociales o físicas, por lo que " $\beta_{x}$ " toma el valor de omisión= 1 .

S $\quad$ indica la sensibilidad del LULC "j" a la amenaza " $r$ ". Si este es igual a cero, entonces "D $D_{x j}$ "no es función de la amenaza " $r$ ".

Para alimentar el modelo, se obtuvo la ubicación espacial de las actividades antropogénicas sugeridas por Tallis et al. (2010) como amenazantes a los hábitats, así como los disturbios, representados en esta investigación por zonas incendiadas -independientemente de su origen-. Las amenazas identificadas (Tabla 2) fueron integradas en mapas con formato grid de ESRI, las cuales se describen posteriormente. Además, se les ingresaron los elementos: a) distancia máxima estimada de afectación a la calidad del hábitat (cuyo impacto llega a cero al alcanzar esa distancia); b) peso ponderado de la amenaza sobre esa calidad, con relación a otras amenazas; y c) forma de disminución a través del espacio (1= linear, con afectación proporcional en toda la distancia; $\mathrm{O}=$ exponencial, con afectación sensiblemente superior con la cercanía).

Tabla 2. Importancia relativa, distancia de afectación y forma de decaimiento de las amenazas evaluadas en la cuenca

\begin{tabular}{|c|c|c|c|c|}
\hline \multirow{2}{*}{ Identificador } & Amenaza al hábitat/LULC & $\begin{array}{c}\text { Distancia } \\
\text { máxima (km) }\end{array}$ & $\begin{array}{c}\text { Importancia } \\
\text { relativa }\end{array}$ & $\begin{array}{c}\text { Forma de } \\
\text { Decaimiento }\end{array}$ \\
\hline URB & $\begin{array}{c}\text { Mancha urbana (incluye actividades } \\
\text { industriales) }\end{array}$ & 10 & 1 & 1 \\
\hline INC & Incendios (áreas propensas) & 10 & 1 & 1 \\
\hline AGR & Agricultura de Riego & 8 & 0,7 & 1 \\
\hline CMP & Actividades de campismo & 5 & 0,7 & 0 \\
\hline XTR & Extracción ilegal de flora y fauna & 5 & 0,8 & 0 \\
\hline MIN & Actividades mineras & 4 & 0,8 & 1 \\
\hline CPV & Carreteras pavimentadas & 4 & 0,8 & 1 \\
\hline AGTA & Agricultura de secano (anual) & 4 & 0,5 & 0 \\
\hline PZC & Pastizal cultivado & 4 & 0,3 & 0 \\
\hline AGTP & Agricultura de secano (permanente) & 2 & 0,5 & 1 \\
\hline CTR & Caminos de terracería & 2 & 0,5 & 1 \\
\hline
\end{tabular}

Fuente: elaboración propia 
La forma de integrar los mapas de amenazas fue la siguiente: las manchas urbanas son amenazas entendidas como los asentamientos humanos y sus actividades industriales, las que representan el mayor nivel de importancia relativa en contra de los hábitats del área de estudio. Se les asignó el 100\% de la importancia (integrado como el valor máximo de 1 en el modelo) debido a que, entre otros factores de riesgo a los ecosistemas a su alrededor, generan altas cantidades de desechos, contaminación lumínica, visual y auditiva, así como atracción de fauna nociva para especies locales. A este factor amenazante se le otorgó una distancia máxima de afectación de 10 km, con una forma de decaimiento lineal, como indica Tallis et al. (2010).

Otro factor amenazante con la mayor importancia relativa fue el de riesgo de incendios, que se integró al modelo como las zonas con mayor propensión a incendiarse, y con los mismos valores que los de las manchas urbanas. Se consideraron como los tipos de vegetación clasificados con riesgo "alto" y "muy alto" de incendio por el Atlas de Riesgos de Tamaulipas (Gobierno del Estado, 2011). En la vegetación con riesgo "muy alto" se incluyeron BP, BPE y BEBPEvs; la de riesgo "alto" fue: BE, BMM, BT, MSM, SAMS, SBC, SBCvs, SBEhzch, SMSC y PALM.

Para integrar las actividades agropecuarias, se utilizaron las clases del LULC que representan la agricultura de riego y de secano, así como el de pastizal cultivado para la actividad ganadera. De acuerdo con Tallis et al. (2010), se asignó a las actividades agrícolas de riego un 70 \% de la afectación relativa a las zonas urbanas, con una distancia del $80 \%$ y la misma forma de decaimiento. Valores más bajos $(50 \%)$ de la importancia relativa se otorgaron a la agricultura de secano, que también contribuye con productos químicos artificiales al ecosistema, así como afectaciones por movimiento de vehículos a las zonas, pero en menores densidades.

Para asignar los valores de las distancias a las otras actividades agropecuarias, a los sistemas anuales se les otorgó un valor de la mitad de los de riego (40\%), y de una cuarta parte de ellos (20 \%) a los sistemas permanentes. Esto porque se supone que los "hábitats" que significan los sistemas anuales es destruido cada ciclo, con actividades similares a las de riego, y por lo tanto, con el mismo tipo de decaimiento; por su parte, a los permanentes se les asignó el tipo exponencial. Por otro lado, a las zonas pecuarias de pastizal se les dio una importancia relativa de $30 \%$, por su baja densidad en la zona, con distancia y forma de decaimiento iguales a los de los ciclos agrícolas anuales.

Otra forma de amenaza a los ecosistemas que se incluyó fue el campismo, ya que, al no existir restricciones, las personas que lo practican aumentan el riesgo de incendios, a la vez que pueden dañar la vida silvestre y abandonar desechos sólidos. Bajo esta idea, se consideró esta actividad 
con una importancia relativa de $70 \%$, con $50 \%$ en la distancia de afectación y decaimiento exponencial. También se consideraron en esta actividad los sitios con mayor afluencia de paseantes (balnearios en ríos y embalses) por su atractivo y accesibilidad, pero son menos amenazantes a los ecosistemas frágiles, debido a que gran parte de ellos se ubican en las inmediaciones de zonas agropecuarias.

Como no se cuenta con un inventario de sitios atractivos, pero de escasa accesibilidad, se consideró como un indicador de actividades de campo las fotografías de usuarios ubicadas correctamente en el visualizador GoogleEarth ${ }^{\text {TM }}$ (diciembre de 2011), fuera de sitios urbanos o agropecuarios (Figura 3). La información se descargó en formato KML, posteriormente convertida a SHP para obtener un buffer de $2 \mathrm{~km}$. Cabe aclarar que se inventariaron 689 fotografías, en su mayoría situadas en localidades habitadas o áreas agropecuarias, pero sólo se integró en esta evaluación el 37\% de ellas.

Figura 3. Sitios fotografiados por campistas y compartidos en GoogleEarth" (2011)

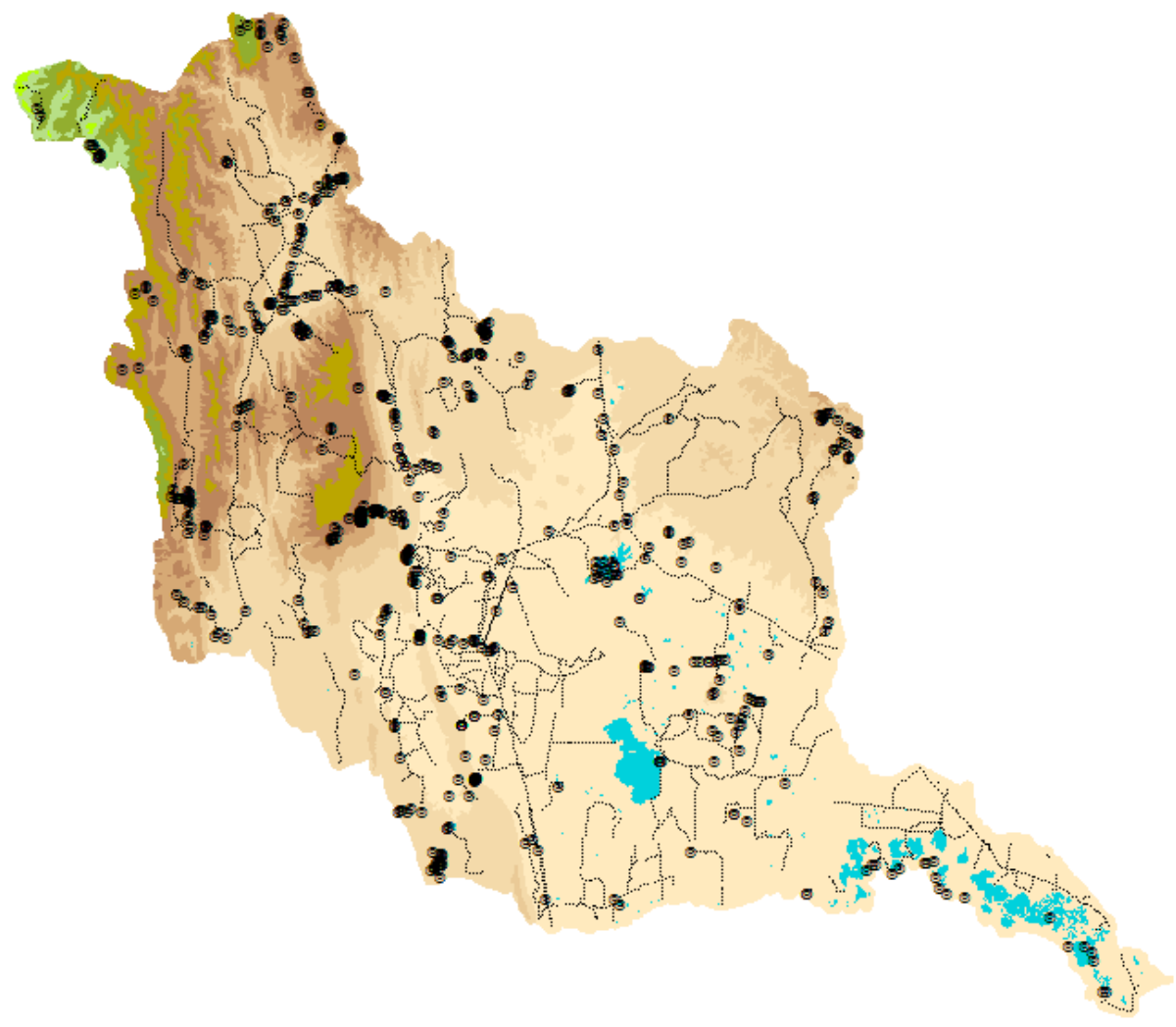

Nota: Las líneas representan las vías de comunicación de todo tipo. Se muestran en azul los cuerpos de agua y en tonalidades beige-marrón los sitios con menor altitud y en verdes las más altas, para dar una idea de la accesibilidad a los sitios.

Fuente: elaboración propia 
Por otra parte, la extracción minera se representó con los sitios reportados por UAT (2001) y SGM (2011), que se ubicaron en el terreno por medio del visualizador de GoogleEarth ${ }^{\text {TM}}$, exportados en .KML y convertidos a SHP para obtener un buffer de un km de cada uno (Figura 4). Se les asignó una importancia de $80 \%$, con decaimiento exponencial, debido a su carácter invasivo y de destrucción completa del hábitat en el sitio donde se lleva esta actividad. Al ser de carácter puntual, la distancia máxima de afectación se consideró 40 \% de la amenaza urbana. Es importante aclarar que las actividades de extracción de petróleo, de gran importancia en Tamaulipas, no se consideran en este estudio debido a que se ubican fuera del área estudiada, frente a las costas del área metropolitana Tampico-Ciudad Madero-Altamira.

\section{Figura 4. Sitios con actividades de extracción minera en la cuenca}

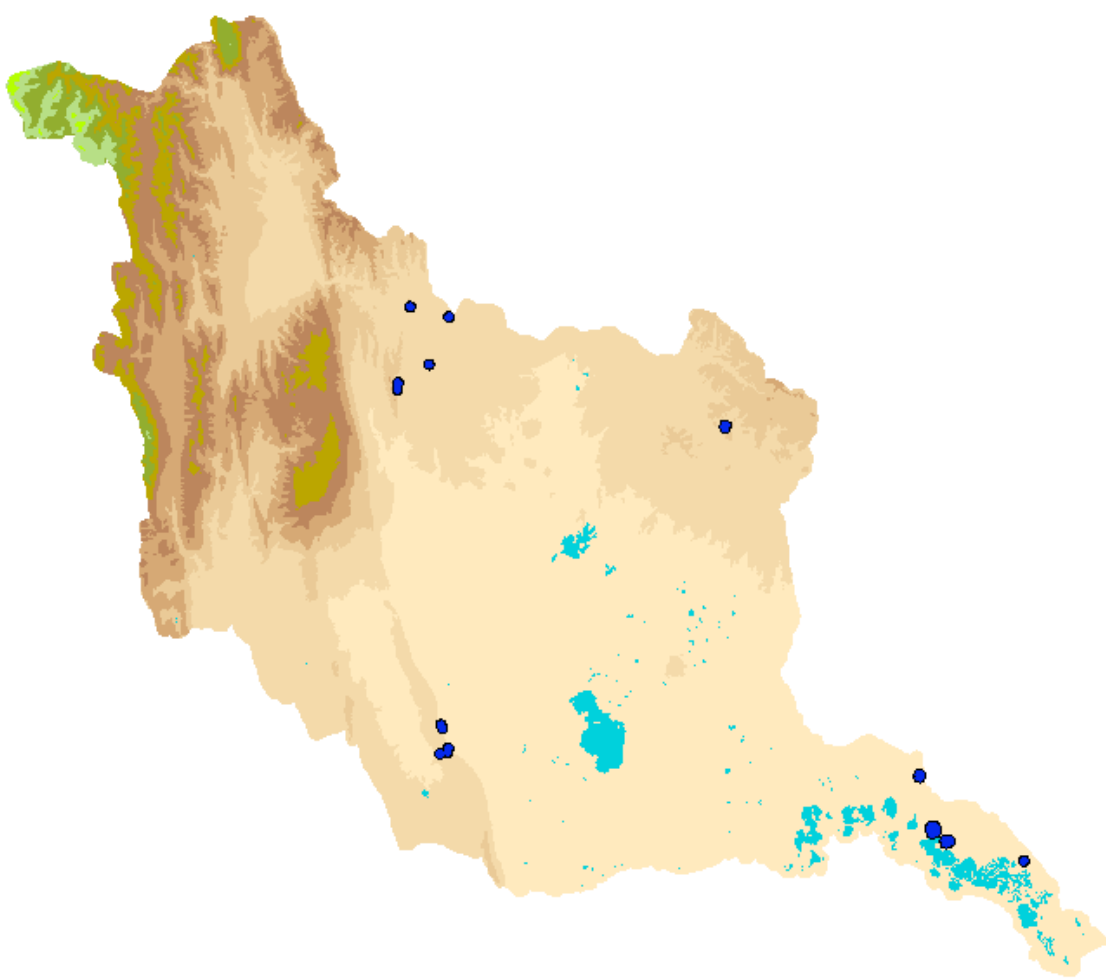

Nota: Se muestran en azul los cuerpos de agua y en tonalidades beige-marrón los sitios con menor altitud y en verdes las más altas, para dar una idea de la accesibilidad a los sitios.

Fuente: elaboración propia, con datos de UAT (2001) y SGM (2011)

Como indicador para representar los lugares de extracción ilegal de flora y fauna, se utilizó la red de caminos secundarios (carreteras de terracería), brechas, veredas y vías férreas. Estas son las formas de acceso a ecosistemas con abundancia de especies atractivas, de interés para el mercado ilegal. Los traficantes utilizan este tipo de accesos debido a que son poco transitadas y raramente vigiladas, respecto a las carreteras pavimentadas, lo que facilita la extracción de ejemplares de los ecosistemas; por ello se construyó un buffer de 1 km a los lados de dichas vías, 
con una distancia máxima de afectación de $5 \mathrm{~km}$ y decaimiento exponencial, considerando que se recorre a pie desde la ruta.

Para este trabajo, se consideró el saqueo a los ecosistemas que son hábitat de especies atractivas y de interés que menciona el Institutito Nacional de Ecología (Naranjo et al., 2009). En el área de estudio, se trata de grupos florísticos como cactáceas, orquídeas y zamiáceas; y faunísticos como aves, reptiles y mamíferos, con la mayoría de sus especies presentes en ecosistemas de montaña (Tabla 3).

Tabla 3. Ejemplos de especies atractivas con extracción ilegal, originarias de diferentes tipos de vegetación de la cuenca Guayalejo-Tamesí

\begin{tabular}{|c|c|c|c|}
\hline Grupo & Ejemplo & $\begin{array}{c}\text { Estatus de protección } \\
\text { (NOM-059- } \\
\text { ECOL2010*) }\end{array}$ & $\begin{array}{c}\text { Tipos de vegetación } \\
\text { asociados }\end{array}$ \\
\hline Cactáceas & Echinocactus platyacanthus & $\begin{array}{c}\text { Endémica, protección } \\
\text { especial }\end{array}$ & MDR, MSM, SBE, SBC \\
\hline Orquídeas & Mammillaria roseoalba & $\begin{array}{c}\text { Endémica, protección } \\
\text { especial }\end{array}$ & SAMS, BMM, BE, SMSP, \\
\hline Zamiáceas & Dioon edule & $\begin{array}{c}\text { Endémica, Peligro de } \\
\text { extinción }\end{array}$ & MDR, SBC, SMSP, BE, BMM \\
\hline Reptiles & Crotaphytus collaris & Amenazada & $\begin{array}{c}\text { MDR, } M D R, M S M, M Z Q, \\
\text { SBE, SBC }\end{array}$ \\
\hline Aves canoras & Cardinalis cardinalis & $\begin{array}{c}\text { Endémica, protección } \\
\text { especial }\end{array}$ & $M D R, M S M, M Z Q$, \\
\hline Aves ornato & Amazona oratrix & Peligro de extinción & $\begin{array}{c}\text { BP, PAL, SAMS, SMSC, } \\
\text { RIPARIA }\end{array}$ \\
\hline Felinos & Panthera onca & Peligro de extinción & SAMS, SBC, SMSC, SBE \\
\hline
\end{tabular}

Fuente: elaboración propia con datos de *SEMARNAT (2010)

A esta amenaza se le asignó una importancia relativa de $80 \%$, puesto que no hay libertad total de extracción, porque en la cuenca las rutas de tráfico hacia los sitios de mercadeo son únicamente carreteras estatales o federales. Estas cuentan con vigilancia policial que desalienta en gran parte este tipo de amenaza; no obstante, habitantes de los municipios de Jaumave y Gómez Farías -que pidieron anonimato- expresaron que, en el caso de cactáceas, los traficantes extranjeros les compran semillas de ciertas especies, con lo que pueden evadir mejor a las autoridades de vigilancia.

Finalmente, las vías de tránsito en carretera pavimentada representan una amenaza al hábitat con un efecto zonal que puede ser de hasta $5 \mathrm{~km}$ alrededor de dicha vía (Coffin, 2007). Aunque sus efectos por densidad de tráfico y velocidad inciden directamente sobre la fauna, otros efectos también se presentan en vías de terracería, tales como ruido, vibraciones, desechos sólidos, 
líquidos o riesgo de incendio; y otros son propios de esta vía como la dispersión de polvo a ambos lados de la vía.

Por estas razones, se generó un buffer de 4 km de las vías pavimentadas y de $2 \mathrm{~km}$ sobre las de terracería, considerando también menor existencia de infraestructura y de periodicidad en su mantenimiento. El decaimiento de la amenaza se evaluó como de tipo lineal para los dos tipos de vía, con importancia relativa de $80 \%$ para las pavimentadas y $50 \%$ para terracerías. Las vías férreas no se evaluaron como tal, puesto que en el área de estudio va paralela a la pavimentada, dentro de la zona de afectación.

Otro de los requisitos de entrada del modelo es la evaluación de las clases de hábitat, de acuerdo con la sensibilidad relativa de cada clase ante cada amenaza $\left(S_{j r}\right.$, que toma valores de 0 para la más amenazada, y 1 para la menos). Esta sensibilidad puede entenderse en algunos casos como la probabilidad que tiene el hábitat de convertirse al uso que representa la amenaza (por ejemplo, agrícola o urbano). La sensibilidad de los usos antropogénicos ante la amenaza representada por sí mismo es igual a 1. La Tabla 4 indica la sensibilidad del hábitat a cada una de las amenazas identificadas.

Tabla 4. Sensibilidad relativa de los LULC

a cada tipo de amenaza presente en la cuenca (en términos relativos: 0 a 1)

\begin{tabular}{|c|c|c|c|c|c|c|c|c|c|c|c|c|}
\hline \multirow{2}{*}{ LULC } & \multicolumn{10}{|c|}{ Sensibilidad relativa a cada amenaza } \\
\cline { 2 - 12 } & URB & AGR & PZC & AGTA & AGTP & CMP & INC & MIN & XTR & CPV & CTR \\
\hline AGR & 0,00 & 1,00 & 0,70 & 0,70 & 0,00 & 0,00 & 0,00 & 0,50 & 1,00 & 0,50 & 0,70 \\
\hline AGTA & 0,50 & 0,50 & 0,50 & 1,00 & 0,50 & 0,50 & 0,50 & 0,30 & 0,80 & 0,50 & 0,70 \\
\hline AGTApzi & 0,50 & 0,50 & 0,50 & 1,00 & 0,50 & 0,00 & 0,00 & 0,30 & 0,30 & 0,50 & 0,50 \\
\hline AGTP & 0,70 & 1,00 & 1,00 & 1,00 & 1,00 & 0,80 & 0,30 & 0,50 & 0,80 & 0,50 & 0,70 \\
\hline AGUA & 1,00 & 1,00 & 1,00 & 1,00 & 0,70 & 0,50 & 1,00 & 0,50 & 0,50 & 0,70 & 0,70 \\
\hline BE & 0,00 & 0,50 & 0,50 & 0,30 & 0,20 & 0,20 & 0,00 & 0,20 & 0,00 & 0,20 & 0,30 \\
\hline BEBPEvs & 0,00 & 0,50 & 0,50 & 0,30 & 0,20 & 0,20 & 0,00 & 0,20 & 0,00 & 0,20 & 0,30 \\
\hline BMM & 0,00 & 0,50 & 0,50 & 0,50 & 0,40 & 0,10 & 0,00 & 0,50 & 0,00 & 0,20 & 0,30 \\
\hline BP & 0,00 & 0,30 & 0,50 & 0,30 & 0,50 & 0,10 & 0,00 & 0,20 & 0,10 & 0,20 & 0,30 \\
\hline BPE & 0,00 & 0,50 & 0,50 & 0,30 & 0,20 & 0,20 & 0,00 & 0,20 & 0,00 & 0,20 & 0,30 \\
\hline BT & 0,00 & 0,50 & 0,50 & 0,50 & 0,30 & 0,30 & 0,00 & 0,20 & 0,30 & 0,20 & 0,30 \\
\hline DESN & 0,00 & 0,20 & 0,50 & 0,80 & 0,50 & 0,50 & 0,50 & 0,00 & 1,00 & 1,00 & 1,00 \\
\hline INU & 0,20 & 0,30 & 0,50 & 0,50 & 0,50 & 0,30 & 0,80 & 0,00 & 1,00 & 0,80 & 0,80 \\
\hline MAN & 0,00 & 0,00 & 0,40 & 0,70 & 0,50 & 0,10 & 0,50 & 0,00 & 0,10 & 0,00 & 0,30 \\
\hline MDR & 0,00 & 0,20 & 0,60 & 0,50 & 0,20 & 0,50 & 0,00 & 0,50 & 0,00 & 0,00 & 0,30 \\
\hline MSM & 0,00 & 0,30 & 0,30 & 0,20 & 0,20 & 0,50 & 0,00 & 0,30 & 0,00 & 0,00 & 0,30 \\
\hline MZQ1 & 0,00 & 0,20 & 0,40 & 0,10 & 0,00 & 0,50 & 0,00 & 0,50 & 0,00 & 0,00 & 0,30 \\
\hline MZQvs & 0,00 & 0,20 & 0,40 & 0,10 & 0,00 & 0,50 & 0,00 & 0,50 & 0,20 & 0,00 & 0,30 \\
\hline PALM & 0,00 & 0,50 & 0,20 & 0,10 & 0,30 & 0,50 & 0,00 & 0,70 & 0,00 & 0,00 & 0,30 \\
\hline
\end{tabular}


Tabla 4. Continuación

\begin{tabular}{|c|c|c|c|c|c|c|c|c|c|c|c|}
\hline \multirow{2}{*}{ LULC } & \multicolumn{10}{|c|}{ Sensibilidad relativa a cada amenaza } \\
\cline { 2 - 13 } & URB & AGR & PZC & AGTA & AGTP & CMP & INC & MIN & XTR & CPV & CTR \\
\hline PZC & 0,50 & 0,80 & 1,00 & 0,20 & 0,00 & 1,00 & 0,00 & 0,20 & 1,00 & 0,50 & 0,50 \\
\hline PZI & 0,30 & 0,50 & 0,50 & 0,80 & 0,50 & 0,50 & 0,00 & 0,20 & 0,80 & 0,50 & 0,20 \\
\hline QUE & 1,00 & 1,00 & 1,00 & 1,00 & 1,00 & 1,00 & 1,00 & 1,00 & 1,00 & 1,00 & 1,00 \\
\hline RIPA & 0,00 & 0,00 & 0,20 & 0,00 & 0,10 & 0,20 & 0,00 & 0,50 & 0,00 & 0,00 & 0,30 \\
\hline SAMS & 0,00 & 0,50 & 0,50 & 0,50 & 0,30 & 0,20 & 0,00 & 0,50 & 0,00 & 0,00 & 0,30 \\
\hline SBC & 0,00 & 0,00 & 0,00 & 0,00 & 0,00 & 0,50 & 0,00 & 0,50 & 0,00 & 0,00 & 0,30 \\
\hline SBCvS & 0,00 & 0,00 & 0,00 & 0,00 & 0,00 & 0,50 & 0,00 & 0,50 & 0,20 & 0,00 & 0,30 \\
\hline SBEhzch & 0,00 & 0,00 & 0,00 & 0,00 & 0,00 & 0,50 & 0,00 & 0,50 & 0,00 & 0,00 & 0,30 \\
\hline SMSC & 0,00 & 0,20 & 0,20 & 0,10 & 0,10 & 0,50 & 0,00 & 0,50 & 0,00 & 0,00 & 0,30 \\
\hline TUL & 0,00 & 0,10 & 0,70 & 0,70 & 0,70 & 0,80 & 0,50 & 0,00 & 0,10 & 0,00 & 0,30 \\
\hline URB & 1,00 & 1,00 & 1,00 & 1,00 & 1,00 & 1,00 & 1,00 & 1,00 & 1,00 & 1,00 & 1,00 \\
\hline
\end{tabular}

Leyenda: $L_{-}=$sensibilidad del LULC a la amenaza: urb=mancha urbana; agr= agricultura de riego; $p z c=p a s t i z a l e s$ cultivados; agta= agricultura de temporal, cultivos anuales; agtp= agricultura de temporal, cultivos permanentes; $\mathrm{cmp}=$ actividades de campismo; $\mathrm{inc}=$ incendios; $\mathrm{min}=$ minería; $x t r=$ extracción ilegal de flora o fauna; $\mathrm{cpv}=$ carretera pavimentada; ctr= camino de terracería.

Fuente: elaboración propia

Una vez generado el modelo, los ecosistemas se clasificaron de acuerdo con su porcentaje de superficie con algún nivel de degradación (en rangos de porcentaje de superficie degradada). Para estimar el grado de conservación del ecosistema, se plantearon cualitativamente cuatro clases relativas: la de mayor conservación "Muy Alto" se estableció cuando su degradación es nula 0 \% en 80 \% o más de su superficie, y "Alto" cuando existe degradación en el 60 \% a 79 \% de la superficie. En el caso contrario, los hábitats menos conservados, nivel "Bajo", fueron aquellos donde se combinaron los siguientes aspectos: superficie con degradación nula menor a $5 \%$, menor a 40 \% con degradación baja, así como más del 35 \% de su territorio en niveles medios de degradación y con sitios clasificados como altamente degradados. Al resto de los ecosistemas se les otorgó el valor "Medio". La Tabla 5 presenta el criterio para establecer el nivel de conservación relativa de los ecosistemas estudiados. 
Tabla 5. Criterios para establecer el nivel de conservación de los hábitats estudiados, de acuerdo con el porcentaje de su territorio con algún nivel de degradación relativa

\begin{tabular}{|c|c|c|c|c|}
\hline \multirow{2}{*}{$\begin{array}{c}\text { Nivel de } \\
\text { conservación }\end{array}$} & \multicolumn{3}{|c|}{ \% de superficie del ecosistema con algún nivel de degradación } \\
\cline { 2 - 5 } & Nula (0 \%) & Baja (1 \% a 20 \%) & $\begin{array}{c}\text { Media } \\
(21 \% \text { a 69 \%) }\end{array}$ & Alta (> 70 \%) \\
\hline Muy alto & $\geq 80$ & & & \\
\hline Alto & $\geq 60 \leq 79$ & & $\leq 20$ & \\
\hline Medio & & $\leq 40$ & $\geq 35$ & $\geq 0,02$ \\
\hline Bajo & $\leq 5$ & & & \\
\hline
\end{tabular}

Fuente: elaboración propia

\section{Resultados y discusión}

Los niveles de degradación y conservación observados en el presente trabajo evidencian las zonas donde los flujos de SSAA se siguen conservando dentro de la cuenca Guayalejo-Tamesí, en virtud de su aislamiento ante las amenazas antropogénicas analizadas (Figura 5). De acuerdo con Costanza \& Farber (2002), estos sitios pueden considerarse como los de menor fragilidad ecosistémica, puesto que las alteraciones que pudieran cambiar sustancialmente el flujo de SSAA se encuentran a distancias superiores al área expuesta a alteración, y representan la mejor oportunidad para políticas conservacionistas. En la cuenca, estos ecosistemas menos amenazados (degradación nula o menor a 20 \%) ocupan el $77.3 \%$ de su superficie, e incluyen principalmente vegetación de montaña, bosques templados de coníferas y latifoliadas, así como algunas selvas y matorrales semidesérticos.

El modelo de degradación del hábitat generado manifiesta el efecto sinérgico de la conjunción de amenazas sobre los hábitats con menor aptitud -aquellos menos naturales-. Se observa cómo la distribución de las zonas degradadas se relaciona principalmente con los trazos carreteros, que, de acuerdo con Coffin (2007), afectan aumentando su intensidad con la adición de cada factor amenazante. Por ello, resaltan las zonas urbanas y sus inmediaciones, destacando por su superficie los lugares donde concurren áreas de riego agrícola con manchas urbanas, poblados y carreteras; esto coincide con Hou et al. (2016), quienes, con una nueva versión del modelador usado en este trabajo, encontraron una relación inversa en la proporción de áreas residenciales con la disminución de la calidad de los hábitats evaluados.

Por otra parte, el modelo sugiere que una amenaza importante (como la travesía de una carretera), o dos de menor peso (como extracción de especies con actividades de campo), no disminuyen significativamente (en términos relativos) la integridad del hábitat (0 \% a 3 \%). No obstante, la sola travesía carretera delinea la fragmentación de los ecosistemas, lo que, de acuerdo con Coffin 
(2007), es el efecto más obvio de esta amenaza, pues divide las coberturas más amplias o disminuye los parches de ecosistemas; además, otros efectos ecológicos se acumulan cuando se consideran las redes carreteras (Coffin, 2007; Fu et al., 2010), lo que se ve reflejado en el mapa de degradación como "islas" con mayor intensidad de color.

Figura 5. Distribución espacial de los niveles de degradación y amenazas antropogénicas en la cuenca Guayalejo-Tamesí

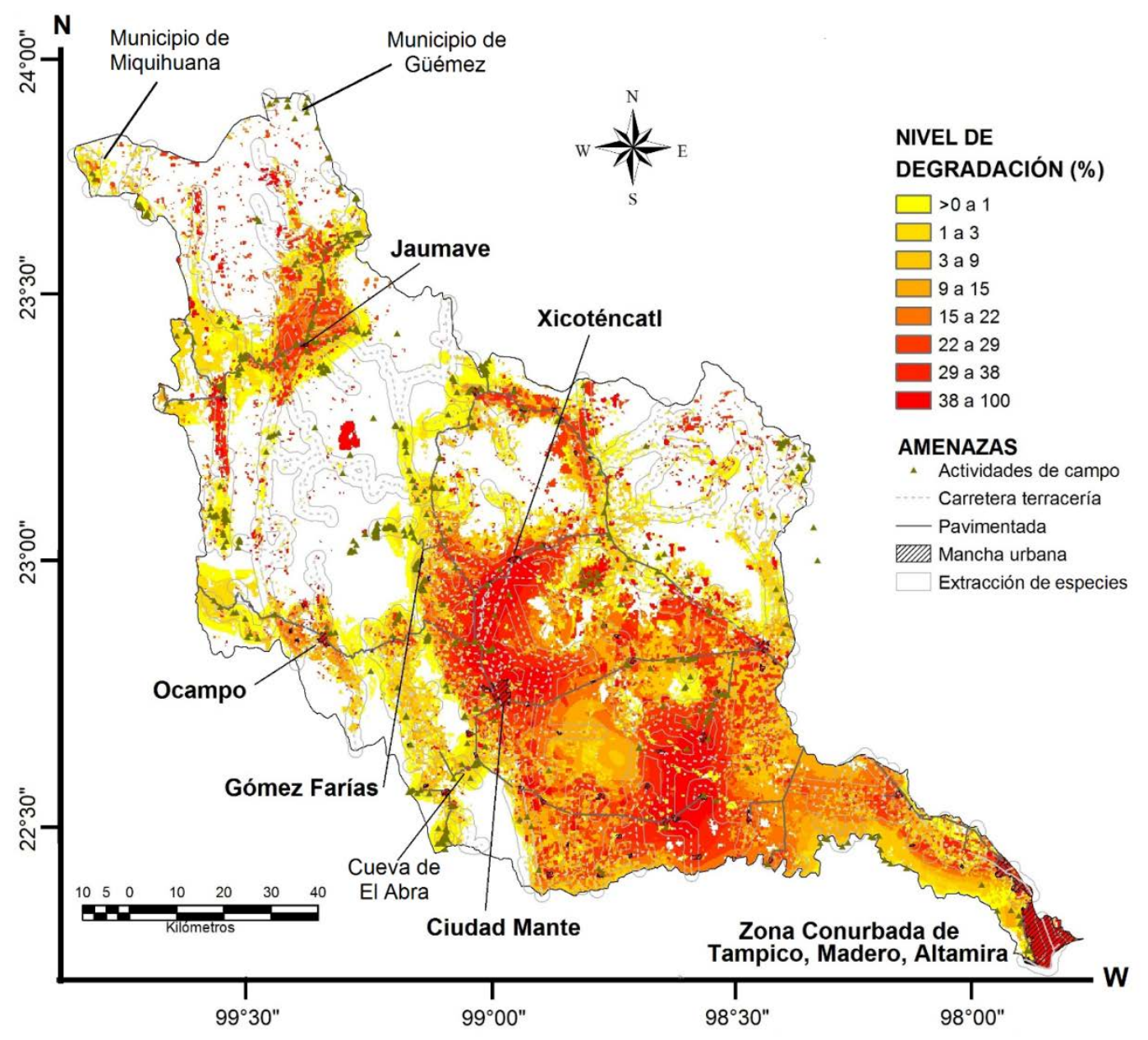

Fuente: elaboración propia

La Tabla 6 muestra los niveles de degradación para cada LULC, donde es evidente que los ecosistemas mejor conservados son boques y selvas. Estos se ubican en las zonas montañosas de la cuenca, lo que coincide con Arunyawat \& Shrestha (2016), quienes usaron la versión 3.0.1 para evaluar la calidad del hábitat en Tailandia, donde los bosques fueron los de mayor conservación en su área de estudio. En la cuenca, tanto las zonas montañosas como los matorrales desérticos de zonas planas, se clasificaron con grado de conservación "muy alto", debido a que el 80 \% o más del ecosistema no presenta degradación. Se observa que, en prácticamente el resto de esos ecosistemas la degradación es baja (de $1 \%$ a 20 \%), pues se trata de ecosistemas prístinos, donde 
sólo una pequeña porción de su territorio (menor de 0.04 \%) presenta degradación muy alta, pero con valores que llegan sólo al $91 \%$.

Tabla 6. Porcentajes de superficie con algún nivel de degradación, en rangos de porcentaje, para cada LULC y su grado de conservación

\begin{tabular}{|c|c|c|c|c|c|c|c|}
\hline \multirow[b]{2}{*}{ LULC } & \multicolumn{6}{|c|}{ Porcentaje de superficie del LULC por rangos de degradación } & \multirow[b]{2}{*}{$\begin{array}{c}\text { Grado de } \\
\text { conservación }\end{array}$} \\
\hline & $0 \%$ & $\begin{array}{l}1 \% \text { a } \\
20 \%\end{array}$ & $\begin{array}{l}\text { Rangos } \\
\text { medios }\end{array}$ & $\begin{array}{c}\text { Degr. (\%) } \\
\text { rangos } \\
\text { medios } \\
\end{array}$ & Rangos altos & $\begin{array}{c}\text { Degr. (\%) } \\
\text { rangos altos }\end{array}$ & \\
\hline BMM & 93,70 & 7,34 & & & 0,03 & $87-91$ & Muy alto \\
\hline BPE & 89,47 & 9,47 & & & 0,01 & $86-87$ & Muy alto \\
\hline SBC & 84,30 & 14,81 & & & 0,01 & $80-81$ & Muy alto \\
\hline BEBPEvs & 84,05 & 10,27 & & & 0,13 & $70-74$ & Muy alto \\
\hline $\mathrm{MDR}$ & 83,83 & 14,89 & & & 0,04 & $61-69$ & Muy alto \\
\hline $\mathrm{BE}$ & 79,30 & 20,20 & & & 0,02 & $86-99$ & Alto \\
\hline SMSC & 76,82 & 22,81 & & & 0,01 & $86-100$ & Alto \\
\hline MSM & 75,62 & 20,21 & & & 0,01 & 80 & Alto \\
\hline RIPA & 75,31 & 5,55 & 16,05 & $40-47^{*}$ & & & Alto \\
\hline SAMS & 73,50 & 25,25 & & & 0,01 & 86 & Alto \\
\hline BP & 69,00 & 21,87 & & & 0,09 & $60-69$ & Alto \\
\hline MAN & 64,20 & $\begin{array}{c}35,80 \\
\left(1 \mathrm{a} 17^{*}\right)\end{array}$ & & & & & Alto \\
\hline MZQ1 & 63,25 & 34,22 & & & 0,05 & 80 & Alto \\
\hline PALM & 46,14 & 52,35 & 0,6 & $35-45^{*}$ & & & Medio \\
\hline SBCvs & 38,96 & 57,66 & & & 0,02 & $80-88$ & Medio \\
\hline PZI & 27,83 & 67,54 & 0,2 & $46-65^{*}$ & & & Medio \\
\hline SBEhzch & 20,37 & 77,67 & & & 0,03 & $70-85$ & Medio \\
\hline MZQvs & 16,29 & 78,46 & & & 0,02 & $81-86$ & Medio \\
\hline BT & 10,84 & 89,04 & 0,08 & $35-55^{*}$ & & & Medio \\
\hline AGTApzi & 10,50 & 82,20 & & & 0,02 & $80-92$ & Medio \\
\hline TUL & 6,34 & 89,66 & & & 3 & $77-79$ & Medio \\
\hline PZC & 4,64 & 87,22 & & & 0,01 & $80-88$ & Medio \\
\hline AGTA & 4,46 & 33,63 & 66,65 & $21-40$ & 0,02 & $81-88$ & Bajo \\
\hline QUE & 4,07 & 7,77 & 39,3 & $21-40$ & 0,64 & $80-85$ & Bajo \\
\hline INU & 3,00 & 82,80 & 1,1 & $41-43^{*}$ & & & Medio \\
\hline DESN & 1,18 & 19,64 & 76,87 & $21-40$ & 0,03 & $71-80$ & Bajo \\
\hline URBA & 1,15 & 3,64 & 44,1 & $41-60$ & 5,35 & $80-100$ & Bajo \\
\hline AGTP & 0,91 & 10,40 & 87,7 & $21-40$ & 0,03 & $82-85$ & Bajo \\
\hline AGR & 0,68 & 27,73 & 52,86 & $21-40$ & 0,02 & $81-87$ & Bajo \\
\hline AGUA & 0,68 & 77,50 & 17,20 & $21-40$ & 0,56 & $71-80$ & Medio \\
\hline
\end{tabular}

Leyenda: verde = muy alto; azul = alto; amarillo = medio; anaranjado = bajo

Nota: * = niveles de degradación más altos alcanzados por el LULC

Fuente: elaboración propia

De acuerdo con Costanza \& Farber (2002), los sitios menos expuestos y, por ende, mejor conservados, pueden considerarse como los de menor fragilidad ecosistémica, puesto que las alteraciones que pudieran cambiar sustancialmente el flujo de SSAA se encuentran a distancias 
superiores al área expuesta a alteración, y representan la mejor oportunidad para políticas conservacionistas. En la cuenca, estos ecosistemas menos amenazados (degradación nula o menor a $20 \%$ ) ocupan el 77,3 \% de su superficie, e incluyen principalmente vegetación de montaña, bosques templados de coníferas y latifoliadas, así como algunas selvas y matorrales semidesérticos.

Debe notarse que los sitios con degradación nula en el área de estudio alcanzan apenas el 0,72\% del territorio (10 714 hectáreas), que en este modelo representan los más conservados. Estos se localizan en las zonas de menor accesibilidad, lejos de vías de comunicación, manchas urbanas y de sistemas agropecuarios extensivos, formando parte de los macizos montañosos (Figura 6). Básicamente las amenazas territoriales a que se enfrentan son incendios de origen natural, como todos los hábitats nativos de la cuenca (Gobierno del Estado, 2011), así como a la extracción ilícita de especies y/o actividades de campismo.

Figura 6. Relación espacial entre los sitios degradación nula (más conservados) y algunos factores de amenaza analizados

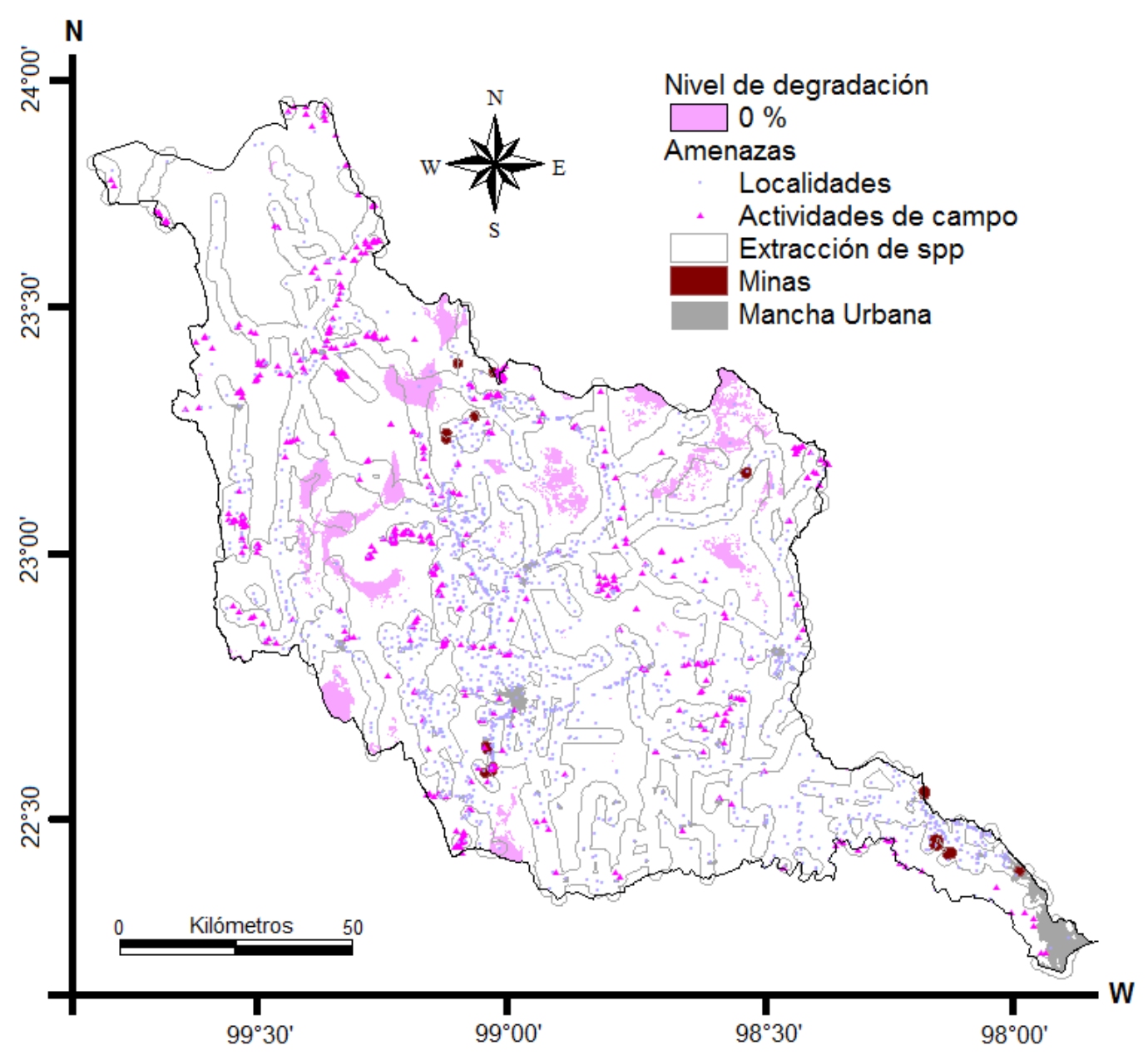

Fuente: elaboración propia 
En la cuenca, los sitios de mejor conservación se encuentran en las zonas más aisladas de las sierras y montañas (Figura 7), a los que sólo se puede acceder por caminos agrestes, brechas y senderos de terracería. Las localidades que se ubican en esos lugares son siempre menores a 100 habitantes, en general con actividades económicas de nivel artesanal o de autoconsumo. Sus amenazas son de carácter natural (incendios, plagas), aunque su belleza paisajística atrae cada vez más al turismo de aventura, como sucede en diversos sitios (Vargas-del-Río, 2016; Trejo \& Marcano, 2016) que los expone a degradarse por actividades de campo mal manejadas (Brenner \& Vargas, 2013); además la presencia de especies atractivas los expone a extracción ilegal de biodiversidad, de acuerdo con Trejo y Marcano (2016).

Figura 7. Ejemplo de un ecosistema con niveles altos de conservación. Bosque de encino en el municipio de Jaumave, con sólo una amenaza a su hábitat identificada (travesía de una brecha transitable sólo con vehículo $4 \times 4$ )

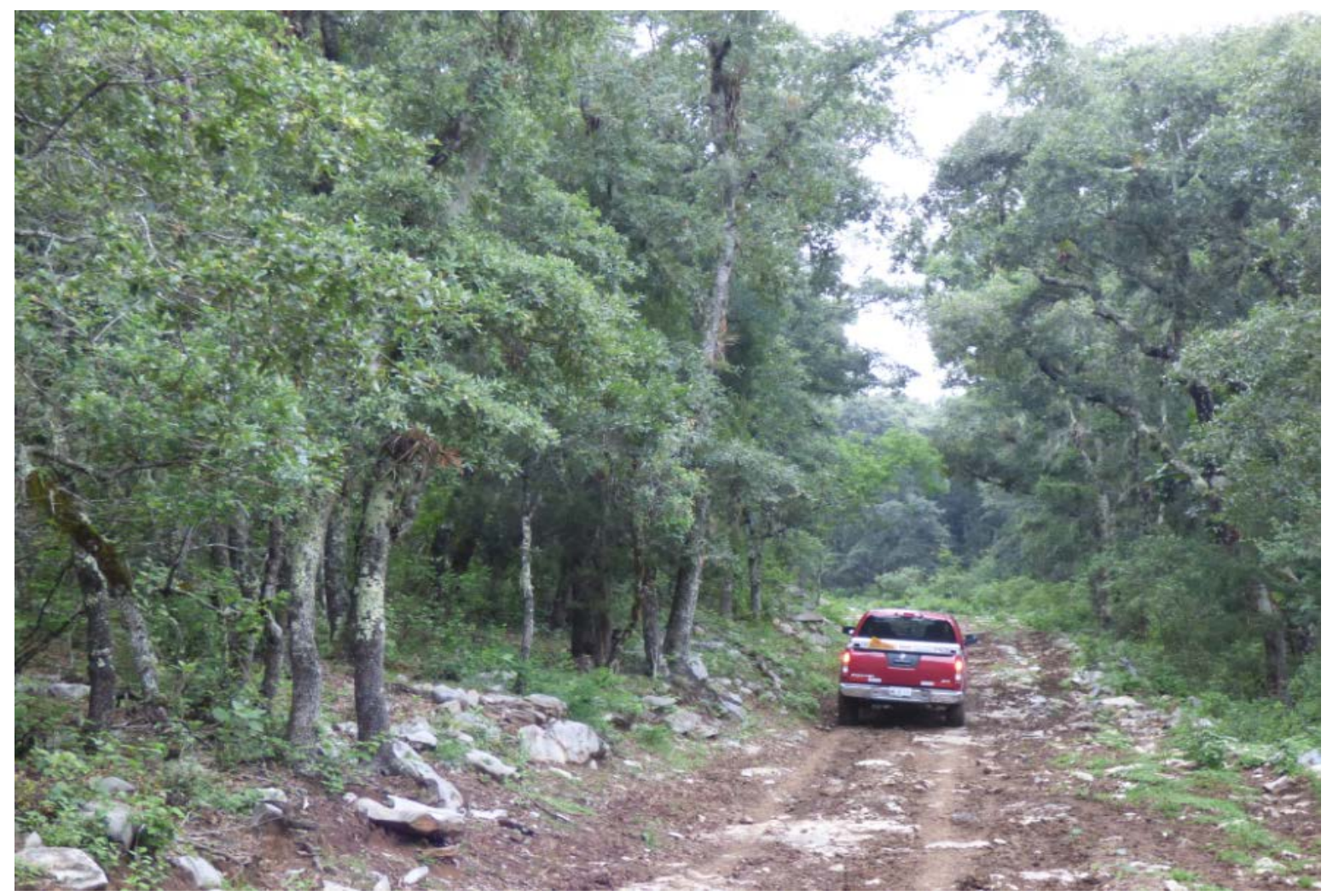

Nota: La cabecera municipal se encuentra a $20 \mathrm{~km}$ en línea recta de este punto, 1000 msnm más abajo, mientras que la localidad más cercana (16 habitantes) se ubica aproximadamente a $3 \mathrm{~km}$.

Fuente: elaboración propia

Es importante mencionar que, de la superficie con mejor conservación de la Cuenca, sólo el 9,2 \% se encuentra bajo protección legal: 0,01\% pertenece al hábitat de manglares, que se encuentra en la NOM-022-SEMARNAT-2003 (SEMARNAT, 2003); menos del 0,01\% son tulares y manglares 
en la Zona Especial sujeta a Protección Ecológica La Vega Escondida; el resto corresponde a los ecosistemas ubicados en la Reserva de la Biósfera "El Cielo". De los ecosistemas que conforman dicha reserva, destaca que poco más del 80 \% del bosque de niebla en la cuenca se encuentra dentro de ella, pero el resto de los hábitats representan menos del 40 \% de su presencia en la misma (Tabla 7). Esto es importante si se considera que las zonas núcleo de la reserva se decretaron (SGG, 1985) para proteger además del mencionado bosque, el de Pinus spp. y Quercus spp. y la selva seca (baja caducifolia y subcaducifolia), por ello es evidente la necesidad de tomar acciones que eviten la degradación de estos ecosistemas fuera de ella.

Tabla 7. Superficie relativa de los hábitats en la cuenca bajo protección oficial en la Reserva de la Biósfera "El Cielo"

\begin{tabular}{|c|c|}
\hline LULC & \% en Cuenca \\
\hline Bosque de niebla (mesófilo de montaña) & 80,10 \\
\hline Bosque de Quercus spp. & 37,47 \\
\hline Selva alta y mediana superennifolia & 34,86 \\
\hline Bosque de Pinus spp. y Quercus spp. & 26,63 \\
\hline Bosque de Pinus - Quercus / Quercus - Pinus con vegetación secundaria & 26,50 \\
\hline Selva mediana subcaducifolia & 19,49 \\
\hline Matorral submontano & 18,50 \\
\hline Bosque de Pinus spp. & 8,53 \\
\hline Selva baja caducifolia y subcaducifolia & 7,18 \\
\hline Mezquital & 5,36 \\
\hline Matorral desértico rosetófilo & 3,78 \\
\hline Selva baja caducifolia y subcaducifolia con vegetación secundaria & 0,02 \\
\hline
\end{tabular}

Fuente: elaboración propia

Los bosques en sucesión que resultaron altamente conservados, en general se ubican en sitios templados, que han sido afectados por factores naturales, básicamente por plagas y por incendios de origen natural (Figura 8), como ocurre generalmente en los ecosistemas nativos de la cuenca (Gobierno del Estado, 2011). Se trata de bosques mixtos de pino y encino, que presentan vegetación secundaria, y se encuentran en diversos grados de sucesión. Dentro de las amenazas antropogénicas que pueden afectar a este hábitat se encuentran la extracción ilícita de especies para su comercio ilegal, así como las actividades de campismo, que incluso podrían estar relacionadas cuando se trata de visitantes con escasos conocimientos y conciencia ambiental (Trejo \& Marcano, 2016). 
Figura 8. Ejemplo de un hábitat con nivel de conservación muy alto.

\section{Bosque mixto de pino y encino con vegetación secundaria, en el municipio de Güémez (extremo noroeste de la Cuenca)}

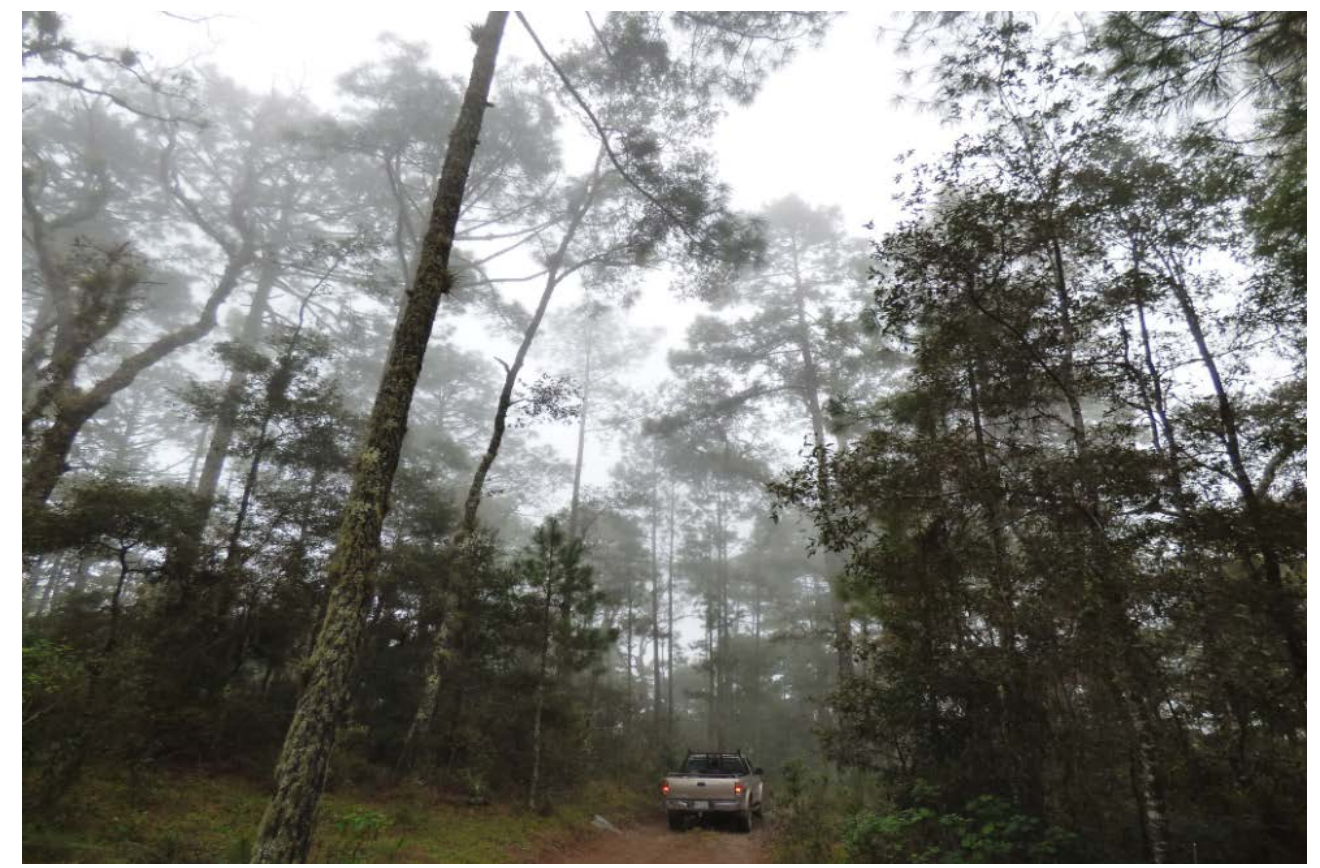

Nota: Se encuentra a 2560 msnm, a 5 km de la localidad Los San Pedros, 1000 msnm más abajo y donde habitan cerca de 60 personas. Su grado de conservación se debe a que se accede por una brecha accidentada, sólo para vehículos todo terreno.

Fuente: elaboración propia

Es de resaltar el hecho de que la cobertura de bosques mixtos de pino y encino con vegetación secundaria se clasifique en el nivel máximo de conservación, lo que puede parecer contradictorio por el hecho de contener vegetación secundaria. No obstante, en algunos sitios de Costa Rica, se ha observado que los bosques expuestos a manejo de impacto reducido -como extracción controlada-, no mostraron diferencia con los prístinos en cuanto a las tasas de mortalidad, pero su nivel de reclutamiento fue superior (Eguiguren, 2013). Sin embargo, el modelo resulta coherente, pues su degradación se estudió por la exposición a las amenazas antropogénicas, y estos ecosistemas cuentan con relativamente poca accesibilidad y se ubican en las partes de mayor altitud y aislamiento de la cuenca,

Al igual que los mejor conservados, los del nivel "alto", en general se ubican en zonas montañosas, con excepción de la vegetación riparia y los manglares. Cabe destacar que este último, además de ser el menos extenso en la cuenca, colinda con la ciudad de Tampico, pero por su ubicación sólo se enfrenta a la mancha urbana como factor de amenaza. Esto puede presentar una debilidad del modelo, pues muestra al manglar como poco amenazado, por lo que, en cuestiones de ordenamiento del territorio, deberán considerarse las manchas urbanas con sus 
amenazas por separado (por ejemplo: lixiviación de contaminantes, dispersión de partículas, ruido, etc.)

Es importante destacar que el manglar es el único LULC del área de estudio con decreto de preservación a través de la mencionada NOM 022, que especifica en su apartado 4.0 literalmente que "El manglar deberá preservarse como comunidad vegetal" (SEMARNAT, 2003), por lo que en una estrategia de manejo debería considerarse dentro del rango más alto de conservación, considerando la superficie menos conservada (cuyo máximo nivel de degradación es bajo: 17\%) como objetivo de restauración. No obstante, la amenaza de la zona metropolitana, el puerto industrial y la extracción de madera para construcción de aparejos pesqueros (casos no documentados por cuestiones de inseguridad social, de acuerdo con entrevistas a ejidatarios, que pidieron el anonimato, 2016) exponen a los manglares a grados altos de estrés, que deberán analizarse a escalas espacio-temporales de mayor detalle.

Con un grado "medio" de conservación, se observan los LULC con 0 \% de degradación en menos de la mitad de su superficie, pero que su mayor parte se encuentra en el rango de 1 a $20 \%$. En este caso se incluyen comunidades vegetales en sucesión, pastizales (cultivados e inducidos) y coberturas primarias expuestas a tres o más amenazas) cuyo rango máximo, con excepción del Tular, no supera 60 \% de degradación); todos ellos, excepto el bosque de Táscate, se encuentran asociados a las zonas planas de la cuenca, en las inmediaciones de zonas agropecuarias y urbanas. Los cuerpos de agua, al ubicarse entre zonas antropogénicas, presentan menos de 1 \% de su cobertura sin degradación, aunque la mayoría se ubica en el rango bajo de ésta (de $1 \%$ a $20 \%$ ).

Ecosistemas secundarios, como los de las selvas semi-secas obtuvieron valores bajos de conservación. Esto se debe a que grandes extensiones de estos hábitats son producto del abandono de terrenos anteriormente dedicados a actividades agropecuarias, que Requena (2013) menciona que casi la mitad ellos presentaban algún nivel de abandono, debido a falta de apoyos, condiciones adversas del mercado internacional y por la inseguridad pública de la zona (García, 2011; Robles, 2018). Esta degradación, al actuar en sinergia con otros factores amenazantes presentes en las zonas donde se ubican, clasifica a estos hábitats con baja calidad para el cumplimiento total de sus SSAA, aunque, de acuerdo con Sotelo-Caro et al. (2015), son de importancia ya que actúan como amortiguador entre áreas fragmentadas,

El efecto de las travesías de carreteras pavimentadas es evidente a través de las sierras, especialmente en donde la afectación de esta infraestructura hace sinergia con otras amenazas, 
como las actividades agrícolas, mineras o de campismo. Este impacto sinérgico destaca en las selvas semi-secas (Figura 9) del centro de la cuenca, donde coinciden extracciones mineras, paso de carreteras y actividades de excursionismo. Un efecto similar fue observado por Sotelo-Caro et al, (2015), quienes refieren que la recuperación de este tipo de hábitats en el estado mexicano de Morelos es complicada, debido a que se encuentran rodeados de áreas urbanas, extracción de madera, zonas agrícolas e infraestructura que los ha fragmentado.

Figura 9. Minería a cielo abierto en el paso de El Abra (Municipio de Antiguo Morelos) y su efecto más visible sobre las selvas semi-secas circundantes: a) extracción minera en mayo, con la selva sin hojas; b) 400 m delante de la anterior, hacia el noreste, se observa la selva cubierta de cal en el mes de diciembre; al fondo de la carretera se encuentra la cueva de El Abra, $800 \mathrm{~m}$ adelante del sitio de la primera fotografía
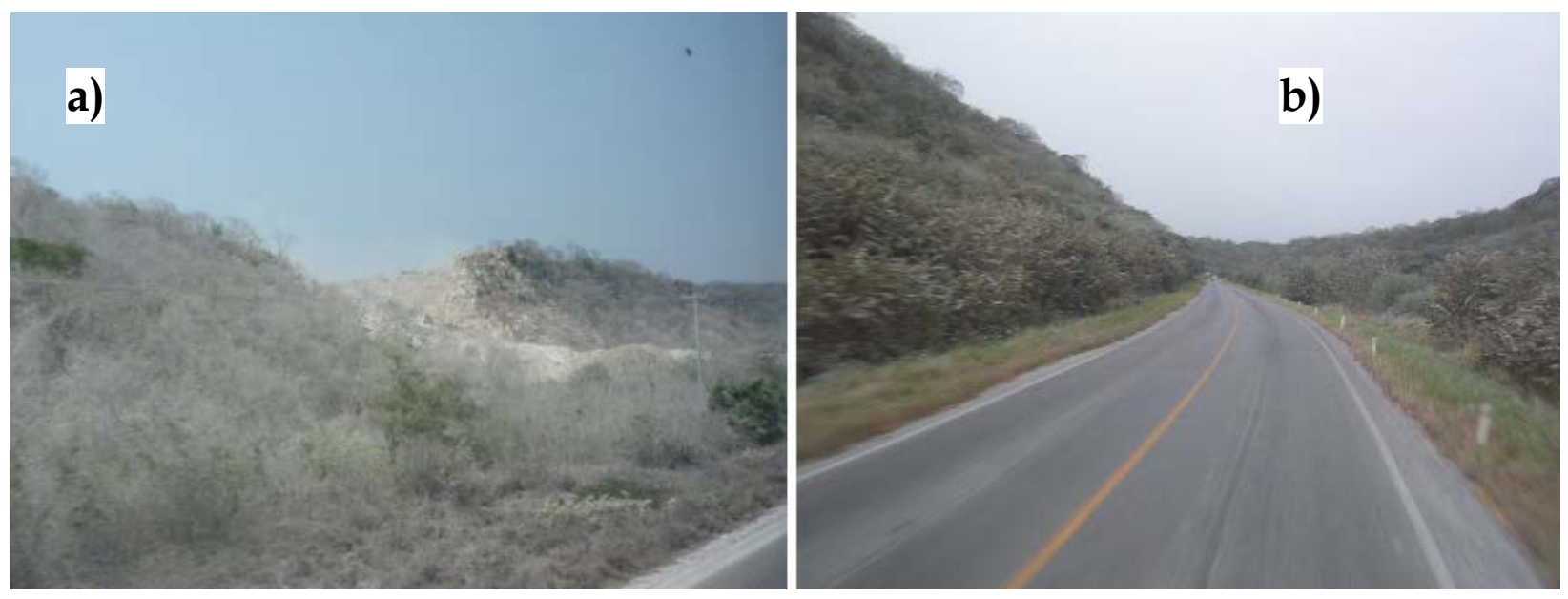

Fuente: elaboración propia

El resto de los LULC representan las áreas quemadas, así como coberturas de carácter antropogénico, como las zonas agropecuarias. La mayor parte del área de estos ecosistemas presenta un rango medio de $21 \%$ a 40 \% de degradación, donde aún pueden tener ciertas funciones de hábitat para especies oportunistas, como refiere Tallis et al., (2010). Aquí la excepción radica en las zonas urbanas, cuya superficie mayoritariamente se encuentra en el rango de $41 \%$ a $60 \%$, y destaca por ser la que cuenta con más territorio (5,35 \%) clasificado en rangos superiores a $80 \%$ de degradación. Aunque no se contabilizan como hábitat, actúan como factor degradante de los adyacentes, y al mismo tiempo se encuentran entre los rangos más altos del mapa de degradación.

Por su parte, las áreas quemadas (Figura 10) no se tomaron como los sitios de amenazas de incendio, debido a su temporalidad, pues su distribución corresponde a octubre de 2011; por 
eso, su presencia no afecta a los hábitats circundantes, Sin embargo, al igual que las manchas urbanas, en el algoritmo carece de puntuación como hábitat, por lo que alcanza los mayores rangos en el mapa de degradación,

Figura 10. Vegetación en distintos niveles de sucesión, tras incendios con varios años de diferencia, en zonas de bosques mixtos de pino y encino del municipio de Miquihuana

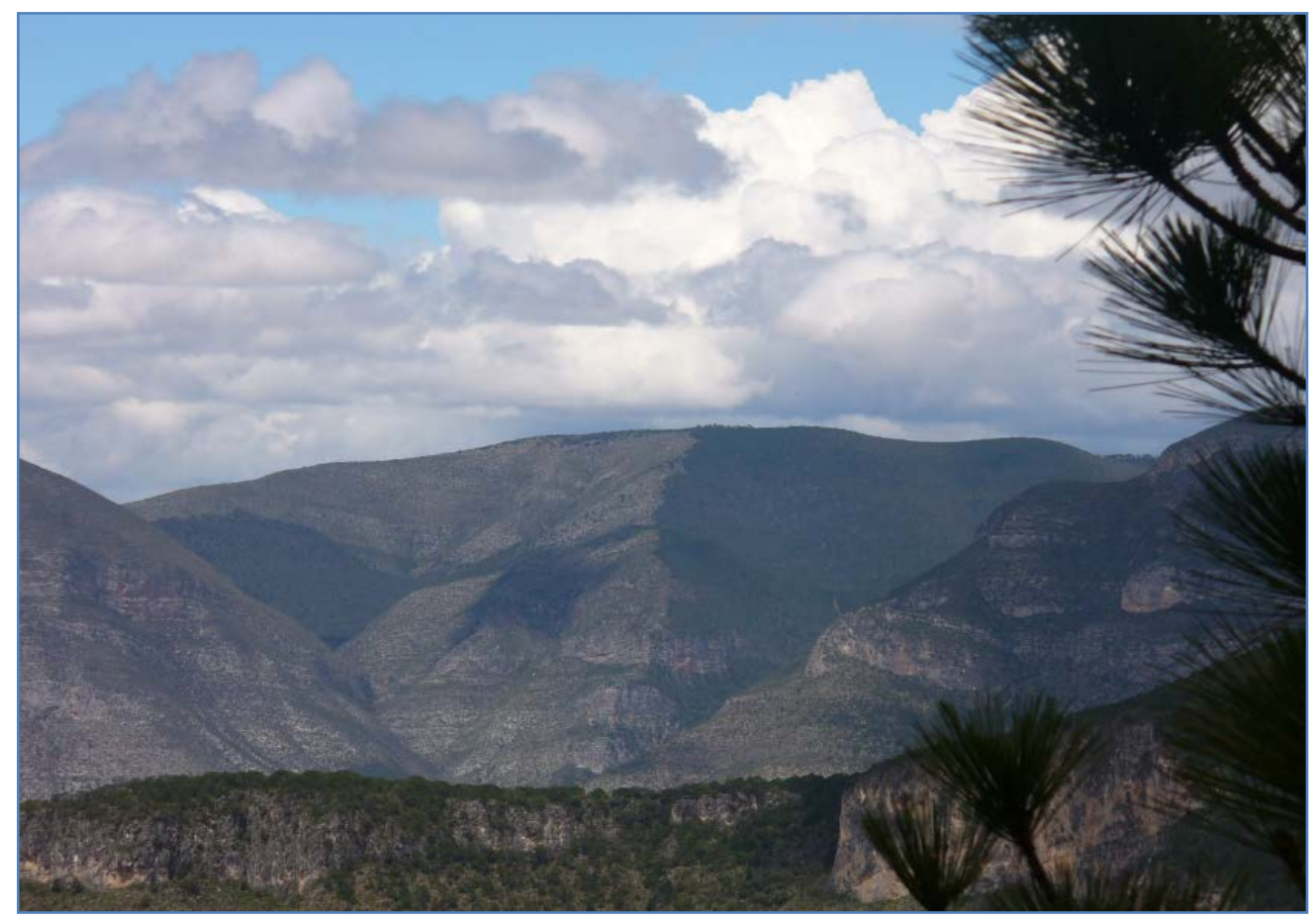

Fuente: elaboración propia

\section{Conclusiones}

La cuenca Guayalejo-Tamesí es un territorio que, no obstante al uso antropogénico de gran intensidad espaciotemporal de sus recursos, cuenta con una importante superficie de ecosistemas bien conservados. Estos sitios cuentan, en el 80 \% de su superficie, con una degradación inferior al $20 \%$, encontrándose aislados, principalmente en las zonas montañosas de la cuenca.

El nivel relativo de conservación de los hábitats estudiados es mayor en sitios montañosos, directamente relacionado con su aislamiento debido a las dificultades de acceso a las actividades humanas. En esos lugares, la degradación como hábitat aumenta solamente fenómenos naturales como incendios o plagas; aunque estas últimas no son tan comunes en esos sitios, por lo que se requeriría de estudios específicos para medir su alcance como factor degradante.

A pesar de su alto grado de conservación, sólo el 9,2% de estos hábitats se encuentra bajo algún tipo legal de protección: el 0,001 \% representa al manglar y el resto a la reserva "El Cielo". Por 
esta razón, quedan expuestos a la ampliación y agravamiento de las amenazas antropogénicas aquí analizadas, lo que se agudiza en las zonas con grado medio de conservación que se encuentran rodeadas por sistemas agropecuarios y otras infraestructuras humanas, como ocurre en los valles más extensos de la Sierra Madre Oriental. Este hecho hace evidente la necesidad de tomar acciones que eviten la degradación de estos ecosistemas fuera de los espacios naturales protegidos del área de estudio.

El modelo de degradación de hábitat, al ser espacialmente explícito, facilita la toma de decisiones de conservación, pues las estrategias de protección y conservación deberían aplicarse a las zonas menos degradadas; mientras que los hábitats de mayor degradación deberán sujetarse, de acuerdo con su nivel, desde políticas de manejo sustentable hasta acciones de restauración de ecosistemas.

Algunos espacios naturales de importancia para ser conservados (como el Cerro del Bernal de Horcasitas, por su valor de identidad) se encuentran expuestos a varios de los factores amenazantes estudiados, por lo que su nivel de degradación aumenta sensiblemente. Esto representa una de las limitaciones del modelo; por ello, en estos casos las estrategias de conservación deberán basarse en otros factores de importancia, como los de identidad o valor para grupos de especies, como las aves o mamíferos.

No obstante las limitaciones del Tier 1 del modelador InVest 1.005beta, este resultó una herramienta práctica y eficiente para definir el nivel de conservación de los ecosistemas estudiados, de acuerdo con las amenazas que le rodean. Una de sus grandes ventajas es que puede aplicarse tanto en decisiones de conservación como en evaluaciones de impacto ambiental de proyectos, ya que representa un método más explícito y cuantitativo que métodos tabulares como la matriz de Leopold comúnmente usada en el país. Sin embargo, para territorios menos extensos, es recomendable integrar información más específica al caso, con escalas más detalladas que resulten en una mayor eficiencia del modelo de degradación del hábitat.

Agradecimientos: Las/os autoras/es agradecen el apoyo del Consejo Nacional de Ciencia y Tecnología (CONACyT) por la beca doctoral número 40654 otorgada a la primera autora, de cuya tesis se desprende este trabajo. Se agradece también el apoyo de: Silvia Lucero Casas González, José Andrés Suárez Fernández y Abelardo Saldívar Fitzmaurice (Universidad Autónoma de Tamaulipas), de Jorge Brenner Guillermo (The Natural Conservacy-Texas) y de Gustavo Limón Camacho. 
Declaración responsable: Las/os autoras/es declaran que no existe ningún conflicto de interés con relación a la publicación de este artículo. La autora Requena Lara realizó todo el proceso metodologico, incluyendo el trabajo de campo, así como el tratamiento de los datos. El Dr. Cámara Artigas apoyó en el trabajo de campo, así como el Dr. Morales, y además este último prestó ayuda en el tratamiento de los datos en el SIG. Y el Dr. Zamora Tovar realizó la revisión final del manuscrito. 


\section{Bibliografía}

Arcos-Espinosa, G., González Turrubiates D., \& Martínez-Cano E. (Comp.) (2017). El Recurso Hídrico en Tamaulipas: la cuenca del río Guayalejo Tamesí. México: Editorial Palibrio.

Adame Garza, J. A., \& Estrada Bellman P. (2003). Efecto de una doble concentración de bióxido de carbono en la atmósfera sobre la disponibilidad de agua en la cuenca del río Guayalejo-Tamesí en el estado de Tamaulipas, México. Revista de Climatología, V3, 27-44. Retrieved from http://journaldatabase,info/articles/efecto_doble_concentracion_bioxido.html

Arcidiacono, A., Ronchia, S., \& Salatab, S. (2016). Managing Multiple Ecosystem Services for Landscape Conservation: A Green Infrastructure in Lombardy Region. Procedia Engineering, 161, 2297-2303. https://doi.org/10.1016/j.proeng.2016.08.831

Arunyawat, S., \& Shrestha, R. P. (2016). Assessing Land Use Change and Its Impact on Ecosystem Services in Northern Thailand, Sustainability, 8(8), 768. https://doi.org/10.3390/su8080768

Baskin, Y. (1997). The work of nature, How the Diversity of life sustain us. Washington, DC: Island Press.

Brenner, L., \& Vargas-del-Río, D. (2013). Community-based ecotourism and environmental protection in Mexico: a synergetic strategy or trendy slogan? In T. Mihalič \& W. C. Gartner (Eds.), Tourism and Developments - Issues and Challenges. Nova Science Publishers, Inc. Retrieved from https://www.researchgate.net/publication/263506120

Carbajal Tradacete, F. J., Sánchez de Llanos J. A., González Burdiel J. L., del Río Benito, Ó., Gonzalvo Navarro J., García Moral F. J., \& Gutiérrez Iglesias D. (2015). Hidrología del Río Pánuco. In Seguridad hídrica del área metropolitana de Monterrey y la cuenca del río Pánuco, Reporte de The Nature Conservancy para Fondo de Agua Metropolitano de Monterrey. Retrieved from http://famm, mx/estudio-de-tnc-seguridad-hidrica-del-area-metropolitana-de-monterrey-y-lacuenca-del-rio-panuco/

Coffin, A. W. (2007). From roadkill to road ecology: A review of the ecological effects of roads, Journal of Transport Geography, 396406. https://doi.org/10.1016/j.jtrangeo.2006.11.006

Costanza, R., \& Farber, S. (2002): Introduction to the special issue on the dynamics and value of ecosystem services: integrating economic and ecological perspectives, Ecological Economics, 47(3), 367-373. Retrieved from

https://www.sciencedirect.com/science/article/pii/S0921800902000873 
Daily, G. C. (1997). Nature's services, Social dependence on natural ecosystems. Washington, D.C.: Island Press.

Eguiguren-Velepucha, P. A. (2013). Los efectos de intervenciones forestales y la variabilidad climática sobre la dinámica a largo plazo de bosques tropicales en el noreste de Costa Rica (MA dissertation, Escuela de Posgrado del Centro Agronómico Tropical de Investigación y Enseñanza, Costa Rica). Retrieved from http://repositorio.bibliotecaorton.catie.ac.cr/handle/11554/7186

Forman, R., Sperling, D., Bissonette, J., Clevenger, A., Cutshall, C., Dale, V., Fahrig, L., France, R., Goldman, C., \& Winter, T. (2003). Road Ecology, Washington, DC: Island Press.

Fu, W., Liu, S., \& Dong, S. (2010). Landscape pattern changes under the disturbance of road networks, Procedia Environmental Sciences, 2, 859-867.

https://doi.org/10.1016/j.proenv.2010.10.097

García de la Llata, H. (2011). Abandonan ganaderos cinco mil ranchos en Tamaulipas. In NOTIMEX. Excélsior. Retrieved from https://www.excelsior.com.mx/node/709505

Grupo Interdisciplinario para el Ordenamiento Territorial (GIOT) (2000). Programa de Ordenamiento Territorial. Guía Metodológica para el Programa Estatal de Ordenamiento Territorial. SEDESOL-SEMARNAP-CONAPO-INEGI, México.

Gobierno del Estado de Tamaulipas (Gobierno del Estado) (2011). Atlas de riesgos del estado de Tamaulipas. Retrieved from http://proteccioncivil.tamaulipas.gob.mx/atlas-de-riesgos-del-estadode-tamaulipas/

Hall, L. S., Krausman, P. R., \& Morrison, M. L. (1997). The habitat concept and a plea for standard terminology, Wildlife Society Bulletin, 25(1): 173-182. Retrieved from http://www.calwater.ca.gov/Admin_Record/C-051437.pdf

Hou, Y., Li, B., Müller, F., Müller, F., \& Chen, W. (2016). Ecosystem services of human-dominated watersheds and land use influences: a case study from the Dianchi Lake watershed in China, Environ, Monit, Assess, 188, 652. https://doi.org/10.1007/s10661-016-5629-0

INEGI, Instituto Nacional de Estadística y Geografía e Informática (1983). Síntesis Geográfica del Estado de Tamaulipas. Secretaría de Programación y Presupuesto, México, D.F.

INEGI (2000). Conjunto Nacional de Datos Vectorial Edafológico. Escala 1:250 000 Serie II (Digital). Retrieved from https://www.inegi.org.mx/temas/edafologia/ 
INEGI (2010). Censo de Población y Vivienda $2010 . \quad$ Retrieved from https://www, inegi,org,mx/programas/ccpv/2010/default,html\#Tabulados.

INEGI (2013). Cartas Digitales del Marco Geoestadístico de México. Retrieved from https://www.inegi.org. mx/temas/mapas/mg/

INFDMP, Instituto Nacional para el Federalismo y el Desarrollo Municipal (2005). Enciclopedia de los Municipios de México, Estado de Tamaulipas, Gobierno del Estado de Tamaulipas. Retrieved from http://www.e-local.gob.mx/work/templates/enciclo/tamaulipas/

Karevia, P., Tallis, H., Ricketts, T. H., Daily, G. C., \& Polasky, S. (Eds.) (2011). Natural Capital, Theory and Practice of Mapping Ecosystem Services. Oxford: Oxford University Press. Retrieved from http://www.oxfordscholarship.com/view/10.1093/acprof:oso/9780199588992.001.0001 /acprof-9780199588992

Kiss, A. (2004). Making biodiversity conservation a land use priority. In T. O. McShane, M. P. Wells (Eds.), Getting Biodiversity Projects to Work: Towards More Effective Conservation and Development. New York: Columbia University Press.

Martín-López, B., Gómez-Baggethun, E., González, J. A., Lomas, P. L., \& Montes, C. (2009). The assessment of ecosystem services provided by biodiversity: re-thinking concepts and research needs. In J. B. Aronoff (Ed.), Handbook of Nature Conservation. Nova Science Publishers, Inc. Retrieved from http://ocw, um,es/ciencias/avances-ecologicos-para-la-sostenibilidad-delos/lectura-obligatoria-1/leccion11/articulo-funciones-servicios-conceptos, pdf, Fecha de consulta:

Martínez Laguna, N. (2001). Evolución y expresión territorial de la industria petroquímica en México. Investigaciones Geográficas, 46, Retrieved from http://www.investigacionesgeograficas.unam.mx/index,php/rig/article/view/59158/5214 $\underline{5}$

Mckinney, M. L. (2002). Urbanization, Biodiversity, and Conservation: The impacts of urbanization on native species are poorly studied, but educating a highly urbanized human population about these impacts can greatly improve species conservation in all ecosystems. BioScience, 52, 883890. Retrieved from https://academic.oup.com/bioscience/article/52/10/883/354714

Naranjo, E.J., Dirzo, R., López Acosta, J. C., Rendón-von Osten, J., Reuter, A., \& Sosa-Nishizaki, O. (2009). Impacto de los factores antropogénicos de afectación directa a las poblaciones silvestres de flora y fauna. In Capital natural de México, vol, II: Estado de conservación y tendencias de cambio (pp. 247-276). México: CONABIO. 
Moreno Talamantes, A. (2003). Modelo digital de elevación de Nuevo León y Tamaulipas, resolución de 100m, Cortesía de Cantú, C. (Facultad de Ciencias Forestales, Universidad Autónoma de Nuevo León). Linares, México (Unpublished).

Nelleman, C., Kullered, L., Vistnes, I., Forbes C., Husby, E., Kofinas, G. P., ... T. S. Larsen (2001). Global Methodology for mapping human impacts on the biosphere. United Nations Environment $\begin{array}{lllll}\text { Program; } & \text { Report } & \text { UNEP/DEWA/TR, } & 51 & \text { pp. }\end{array}$ from https://www.globio.info/downloads/218/globioreportlowres.pdf

Nelson, E., Cameron, D. R., Regetz, J., Polasky, S., \& Daily, G. C. (2011). Terrestrial Biodiversity. In P. Kareiva, H. Tallis, G. Daily, T. Ricketts \& S. Polasky (Eds.), Natural Capital: Theory and Practice of Mapping Ecosystem Services. Oxford University Press. https://doi.org/10.1093/acprof:oso/9780199588992.003.0013

OEIDRUS, Oficina Estatal de Información para el Desarrollo Rural Sustentable. (2011). Boletín de la OEDRIUS, Avances Estadísticos del Sector Rural de Tamaulipas. Vol 5, N 3, Mayo-Junio 2011, Gobierno del Estado de Tamaulipas y SAGARPA. Retrieved from http://www.campotamaulipas.gob.mx/boletines/BOLETIN_OEIDRUS_V5_3.pdf

Periódico Oficial de Tamaulipas (POT). 1985. Decreto expedido por el Ejecutivo del Estado, por medio del cual por causa de utilidad pública, se declara área ecológica protegida, clasificada como Reserva de la Biosfera denominada "El Cielo". Secretaría General del Gobierno del Estado de Tamaulipas (SGG).

Ramírez Fernández, J. A., \& Jenchen, U. (2016). Cinturones orogénicos sepultados bajo la Sierra Madre Oriental: basamento precámbrico y paleozoico. Ciencia UANL, 19(80), 4753. http: //cienciauanl.uanl.mx/?p=6018

Requena-Lara, G. N. (2007). Diagnóstico Ecológico de la Cuenca Guayalejo-Tamesí con Base en Sistemas de Información Geoespacial (MA dissertation, Instituto Tecnológico de Ciudad Victoria, Ciudad Victoria, Tamaulipas, México). Retrieved from http://www.itvictoria.edu.mx/

Requena-Lara, G. N. (2013). Uso de un sistema de información geoespacial para la evaluación socioeconómica de los servicios ambientales en la Cuenca Guayalejo-Tamesí (Tamaulipas, México). (Doctoral dissertation, Universidad de Sevilla, Spain). Retrieved from https://www.educacion.gob.es/teseo/imprimirFichaConsulta.do; jsessionid=96D4D1D5856 9B3671791F3AD93957D70? idFicha=352625 
Robles, A. (2018). Cinco mil ranchos ganaderos en Tamaulipas han cesado su producción. In Expreso.press. Retrieved from https://www.ganaderia.com/destacado/Cinco-mil-ranchosganaderos-en-Tamaulipas-han-cesado-su-produccion

Rzedowski, J. (2006). Vegetación de México. Primera Edición Digital, CONABIO. Retrieved from https://www.biodiversidad.gob.mx/publicaciones/librosDig/pdf/NegetacionMx_Cont.pdf

Secretaría de Agricultura, Ganadería, Desarrollo Rural, Pesca y Alimentación (SAGARPA) (2004). Anuario de Estadísticas Agropecuarias de Tamaulipas. Documento oficial de OEIDRUS Tamaulipas.

SEMARNAT, Secretaría de Medio Ambiente y Recursos Naturales (2003). NORMA Oficial Mexicana NOM-022-SEMARNAT-2003, Que establece las especificaciones para la preservación, conservación, aprovechamiento sustentable y restauración de los humedales costeros en zonas de manglar. Diario Oficial de la Federación del jueves 10 de abril de 2003. Primera Sección: 16-41.

SEMARNAT (2010). Norma Oficial Mexicana NOM-059-SEMARNAT-2010, que establece la Protección ambiental- Especies nativas de México de flora y fauna silvestres-Categorías de riesgo y especificaciones para su inclusión, exclusión o cambio-Lista de especies en riesgo. Diario Oficial de la Federación del jueves 30 de diciembre de 2010. Segunda Sección.

Servicio Geológico Mexicano (SGM) (2011). Panorama minero del Estado de Tamaulipas. Coordinación General de Minería. Retrieved from http://www.sgm.gob.mx/pdfs/TAMAULIPAS.pdf

Sotelo-Caro, O., Chichia-González, J., Sorani, V., \& Flores-Palacios, A. (2015). Cambios en la dinámica de deforestación de la subcuenca de un río en México: la imposibilidad de recuperación de los hábitats originales después del cese de la deforestación. Revista de geografía Norte Grande, 61, 221-227. Retrieved from http://dx.doi.org/10.4067/S0718-34022015000200012 Tallis, H.T., Ricketts, T., Nelson, E., Ennaanay, D., Wolny, S., Olwero, N., \& Kennedy, C. (2010). INVEST 1,005 beta User's Guide. Stanford: The Natural Capital Project. Retrieved from http://invest.ecoinformatics.org

Toledo-Manzur, V. M. (1998). Diagnóstico de los escenarios de la biodiversidad de México a través de un sistema de información ecogeográfica. Universidad Nacional Autónoma de México. Centro de Investigaciones en Ecosistemas. Informe final SNIB-CONABIO proyecto No. A006, México D. F. Retrieved from http://www.conabio.gob.mx/institucion/cgi$\underline{\text { bin } / \text { datos.cgi? } \text { Letras }=A \& N u m e r o=6}$ 
Trejo-Castro, J. A., \& Marcano-Navas, N. (2016). Ecoturismo y Geoturismo: alternativas estratégicas para la promoción del turismo ambiental sustentable venezolano. Revista de Investigación, 40, 202-228. https://www.redalyc.org/articulo.oa?id=376147131011

Universidad Nacional Autónoma de México (UNAM) (2000). Carta digital del Inventario Nacional Forestal (INF). México, DF.

Universidad Autónoma de Tamaulipas (UAT) (2001). Diagnóstico Ecológico del Estado de Tamaulipas. Documento inédito de reporte de proyecto. Ciudad Victoria, México.

Vargas-Del-Río, D. (2016). Embelleciendo de las ruralidades de México para su consumo turístico. Presented at $V$ Congreso Nacional de Ciencias Sociales, La agenda emergente de las ciencias sociales, Conocimiento, crítica e intervención. Guadalajara, Jalisco, March 14-19. Retrieved from https://www.comecso.com/wp-content/uploads/2015/06/Convocatoria-5-CongresoNacional-COMECSO2.pdf

Vera Vázquez, R. (2004). La cuenca del río Guayalejo-Tamesí, situación actual políticas públicas y perspectivas. El Colegio de Tamaulipas, A.C. 